\title{
Wall-to-solid heat transfer coefficient in flighted rotary kilns: experimental determination and modeling
}

\author{
Alex Stéphane BONGO NJENG, Stéphane VITU, Marc CLAUSSE, \\ Jean-Louis DIRION, Marie DEBACQ \\ Conservatoire National des Arts et Métiers, Laboratoire CMGPCE (EA7341), \\ 2 rue Conté, 75003 Paris, France \\ Université de Toulouse, Mines Albi, CNRS UMR 5302, Centre RAPSODEE, \\ Campus Jarlard, 81013 Albi cedex 09, France \\ Université de Lyon, CNRS, INSA-Lyon, CETHIL, UMR5008, \\ Centre de Thermique de Lyon, 69621 Villeurbanne, France
}

25 October 2017

\begin{abstract}
A series of experiments were carried out on an indirectly heated pilot scale rotary kiln. These experiments aimed at recording, while the solids flow, the temperature profiles of the freeboard gas, the solid particle bulk and the wall, as well as the power supplied for heating, over a range of operating conditions. Based on these data, the experimental wall-to-solid heat transfer coefficient was determined through an energy balance. The effects of operating conditions, namely rotational speed, filling degree, lifter shape and controlled temperature, on the heat transfer coefficient are discussed. A model based on dimensional analysis is proposed to calculate the wall-to-solid heat transfer coefficient for low to medium heating temperatures $\left(100-500^{\circ} \mathrm{C}\right)$. The experimental and calculated results are in good agreement. The experimental results are also compared to the predictions of some existing models. While the predictions are within a reasonable order of magnitude with regard to the experimental results, these models fail to represent actual variations with operating conditions satisfactorily

rotary kiln; heat transfer coefficient; wall-to-solid heat transfer; dimensional analysis; lifter; bed depth profile
\end{abstract}

\section{Introduction}

Indirectly heated rotary kilns are widely used as heat exchangers, calciners, incinerators, coolers or dryers. They are usually designed for applications needing tight control and clean heating of materials. Possible applications include [1]: calcination $[2,3,4]$, reduction [5, 6], controlled oxidation, carburization, solid-state reaction $[7,8]$, drying $[9,10]$ or waste disposal $[11,12]$. When operated at atmospheric pressure, these units consist of a cylindrical shell that can be slightly inclined, into which the solid burden is fed continuously at one end and discharged at the other. They are usually equipped with lifting flights or lifters, and/or an exit dam at the kiln outlet end. These units can be classified in two main heating modes, namely directly heated [13] or indirectly heated [14], depending on the location of the heating source with respect to the kiln tube wall. They are very useful reactors with relatively intense heat and mass transfer, capable of handling large amounts of material. Typical industrial indirectly heated rotary kilns are usually smaller than directly heated ones. The heating system installed at the outer wall of the cylindrical shell can be either electrical or gas fired, and is usually designed so that different zones of the kiln can be heated at different controlled temperatures.

Heat transfer in rotary kilns is very complex and may involve the exchange of energy via all the fundamental transfer mechanisms, i.e. conduction, convection, and radiation. A significant amount of research [15] has been completed to determine heat transfer coefficients or the heat fluxes related to the different modes of heat transfer occurring in rotary kilns; unfortunately the heat transfer mechanisms have not been fully clarified. Most of the experimental apparatus used to study the heat transfer mechanisms in particular from wall-to-solid are batch-fed and indirectly heated, as reported in previous work [16, 17, 18, 19, 20]. 
However, it is reported that in rotary kilns the heat transfer is dependent not only on the rotational speed and the kiln tube diameter, but also on the thermo-physical properties and type of motion of the solids.

Recent papers concern DEM simulations carried out to study heat transfer in rotary kilns (for example $[21,22,23,24])$, but we will focus here on the experimental work.

Two main procedures to determine the wall-to-solid heat transfer coefficient experimentally have been reported: earlier studies $[16,17,25]$ recorded the cooling of solids from a predetermined wall temperature, while recent investigations $[18,19,20,26,27,14]$ mostly recorded the transient evolution of temperatures (wall, gas, and solids) during heating. The coefficient was determined through heat balances under some assumptions. A very recent study [28] focused on a long dryer, but at low temperatures.

Although the heat transfer coefficient between wall and solids plays an important role in the heat transfer - especially when modeling the operation of rotary kilns - few correlations have been proposed in the literature. The penetration theory, widely used in the case of fluidized and fixed beds [29], has been applied several times in previous investigations to determine the overall coefficient of heat transferred between the kiln wall and the bulk bed.

Wes et al. [25] were among the first to use the penetration theory in a rotary kiln with the assumption of equal temperature at the contact point between wall and bulk bed, and considering heat conduction only in the radial direction. The calculations carried out proved that the following analytical formulation is applicable for determining the wall-to-solid heat transfer coefficient:

$$
h_{c w-c b}=2 \sqrt{\frac{k_{b} \rho_{b} c_{p b}}{\pi t_{c}}}
$$

where $k_{b}, \rho_{b}$ and $C p_{b}$ are respectively the thermal conductivity, the density and the heat capacity of the bulk. $t_{c}$ is the time during which a point on the kiln wall is in contact with the solids. [25] validated the applicability of the penetration theory by plotting the experimental results against the square root of the kiln rotational speed at a constant filling degree. The resulting curves were straight lines, implying a proportionality in accordance with theory. Lehmberg et al. [17] assumed the presence of a thin layer at the contact between covered wall and bulk materials, and therefore incorporated an equation of heat flux into the penetration theory to account for the thin gap. There have been other attempts by [30, 31, 32, 33, 34] resulting in sometimes very complex equations.

Tscheng and Watkinson [30] proposed a model established by rewriting the penetration theory in dimensionless form, with the use of published experimental data, from which the following equation was obtained:

$$
h_{c w-c b}=11.6 \frac{k_{b}}{l_{\psi}}\left(\frac{N R^{2}}{a_{b} \psi}\right)^{0.3}
$$

where $l_{\psi}$ is the arc length of the covered wall, $\psi$ is the filling angle, $a_{b}$ is the bed thermal diffusivity, $R$ is the kiln internal radius and $N$ is the rotational speed.

Li et al. [34] proposed an extended model of the penetration theory for the wall-to-solid heat transfer coefficient, encompassing the heat transfer coefficient from the bed surface to the bulk materials, and the advection heat coefficient within the bulk materials. The correlation proposed is as follows:

$$
h_{c w-c b}=\left(\frac{\chi d_{p}}{k_{g}}+\frac{1}{2} \sqrt{\frac{\psi}{2 k_{b} \rho_{b} c_{p b} N}}\right)^{-1}, 0.096<\chi<0.198
$$

where $\chi$ is the thickness of the gas film, $d_{p}$ is the particle size, $k_{g}$ is the gas thermal conductivity. It can be noted that Malhotra and Mujumdar [35] extended the wall surface to the single particle contact heat transfer coefficient known as the first particle heat transfer coefficient to account for different particle geometries.

Equation 2 has been used several times $[4,20,26,27,36,37]$ and can be regarded as quite reliable. However, as shown by $[20,14,38]$, there were often quantitatively significant differences between the models' predictions. In addition, [38] conducted a sensitivity analysis clearly demonstrating that variations in the wall-to-solid heat transfer coefficient significantly impact the predictions of bed temperature profiles.

The goal of the present paper is to describe an experimental procedure for the determination of the wallto-solid heat transfer coefficient in indirectly heated rotary kilns. The kiln used was operated at varying 
operating conditions, namely rotational speed, solid mass flow rate, and temperature $\left(100-500^{\circ} \mathrm{C}\right)$; it was fitted with an exit dam of different heights and equipped or not with lifters of different shapes. As it has been found that the kiln inclination has no significant influence on the heat transfer [30], this parameter was kept constant in this study.

The wall-to-solid heat transfer coefficient evaluated in the present study differs from similar previous investigations by $[25,30,34]$. Preliminary results ([39] chap. 6) about the wall-to-solid heat transfer coefficient were determined through the lumped analysis method, and described the main effects of the operating parameters on the coefficient. However, the simplifying assumptions of this earlier analysis led to much too low values of the wall-to-solid heat transfer coefficient.

\section{Materials and methods}

\subsection{Apparatus and materials}

An indirectly heated pilot scale rotary kiln was used to carry out the investigation of the convective heat transfer between wall and gas, as well as the contact heat transfer between wall and solids. It consists of a feeding system, a rotating tube surrounded by a heating system and followed by a recovery zone, in accordance with the layout presented in Figure 1.

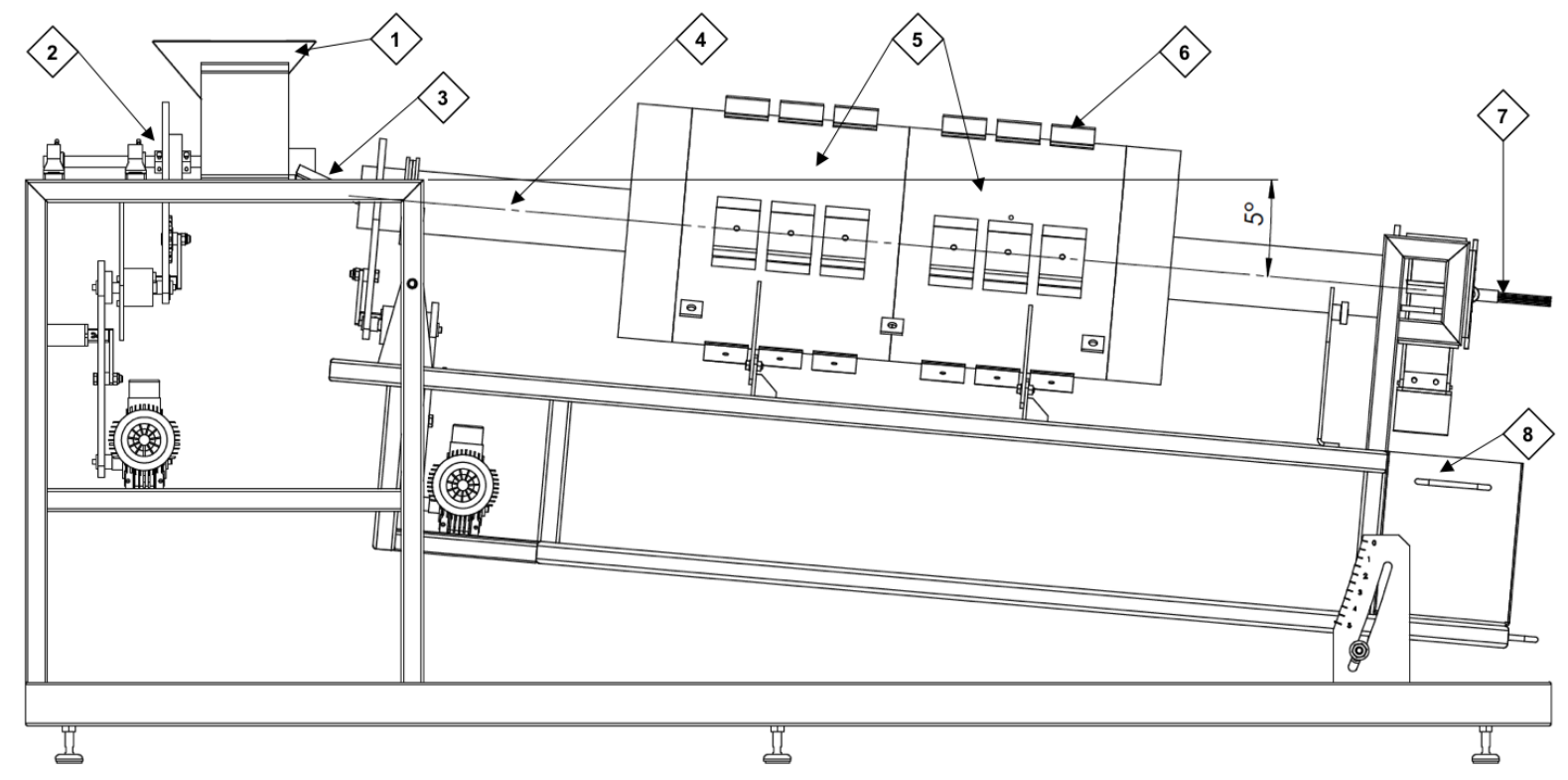

Figure 1: Layout of the experimental apparatus: (1) feed hopper, (2) screw feeder, (3) feed chute, (4) kiln tube, (5) heating system: zones 1 and 2, (6) external thermocouples, (7) measuring rod with thermocouples, (8) storage tank.

The main characteristics of this pilot scale rotary kiln, which was used to investigate the wall-to-solid heat transfer coefficient in the present study, are summarized in Table 1. Its main part consists of a rotating tube supported on 4 rollers. The tube is surrounded by heating elements (resistors) arranged in two zones in line (called respectively zone 1 and zone 2 ) and designed to heat the tube wall up to $1000^{\circ} \mathrm{C}$. The heating elements are covered with a thick layer of insulation. In addition, a hopper and screw feeder are installed upstream of the kiln tube, followed by a feed chute, and a recovery tank is placed downstream of the kiln tube.

The kiln tube rotational speed can be adjusted within 0.5-12 rpm and its slope set at a maximum angle of $5^{\circ}$. Some features such as lifters and dam (Figure 2c) can be fitted respectively to the kiln tube internal wall, and at its outlet end. Figure 2 represents these features which may equip the kiln. Straight one-section $10 \mathrm{~mm}$ lifters (see Figure 2a) referred to as straight lifters (SL) and two-section $10 \mathrm{~mm}$ lifters with a right angle cross section (see Figure 2b) referred to as rectangular lifters (RL), were used.

For the thermal metrology, the experimental unit is equipped with thermocouples (TC) placed at different positions as illustrated in Figure 3 to measure the temperature profiles in the bulk bed, free-board gas and at the wall. Temperatures of the solids and the free-board gas are measured by 20 N-type TC $1.5 \mathrm{~mm}$ in diameter. These thermocouples are installed in a measuring rod and arranged in a series of 5 sections, S1 
Table 1: Characteristics of the experimental setup and order of magnitude of operating conditions.

\begin{tabular}{|c|c|c|c|}
\hline Subsets & Parameters & Order of magnitude & Remarks \\
\hline \multirow{7}{*}{$\begin{array}{l}\text { Rotary kiln } \\
\text { design }\end{array}$} & $\mathrm{D}[\mathrm{m}]$ & 0.101 & Internal Diameter \\
\hline & $\mathrm{L}[\mathrm{m}]$ & 1.95 & Kiln length \\
\hline & Tube thickness [mm] & 6.5 & Inconel alloy \\
\hline & Feed hopper $[\mathrm{L}]$ & 5 & Capacity \\
\hline & Heating zones, length $[\mathrm{m}]$ & $2 \times 0.4$ & In a row \\
\hline & Outer wall TC & 16 & K-type \\
\hline & Measuring rod TC & 20 & N-type \\
\hline \multirow{8}{*}{$\begin{array}{l}\text { Operating } \\
\text { conditions }\end{array}$} & $\mathrm{N}[\mathrm{rpm}]$ & $2-12$ & Rotational speed \\
\hline & $\mathrm{S}\left[^{\circ}\right]$ & 3 & Kiln slope \\
\hline & $\dot{\mathrm{M}}\left[\mathrm{kg} \cdot \mathrm{h}^{-1}\right]$ & $0.5-3.2$ & Mass flow rate \\
\hline & $\mathrm{h}[\mathrm{mm}]$ & $23.5-33.5$ & Exit dam height \\
\hline & Heating temperature $\left[{ }^{\circ} \mathrm{C}\right]$ & $100-500$ & Low to medium \\
\hline & Lifters shape & NL & No lifter, smooth wall \\
\hline & (configuration), & SL (4 rows), 10 & Straight lifter \\
\hline & height $[\mathrm{mm}]$ & $\mathrm{RL}$ (4 rows), 10 & Rectangular lifter \\
\hline
\end{tabular}

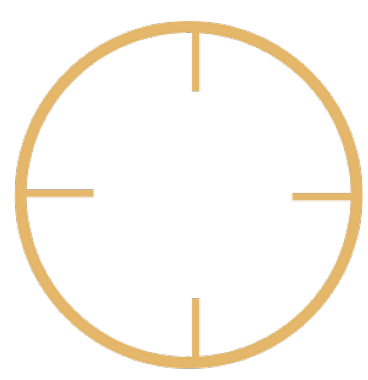

(a) SL.

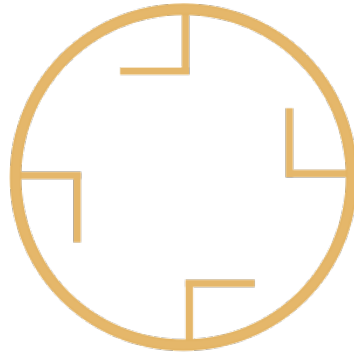

(b) RL.
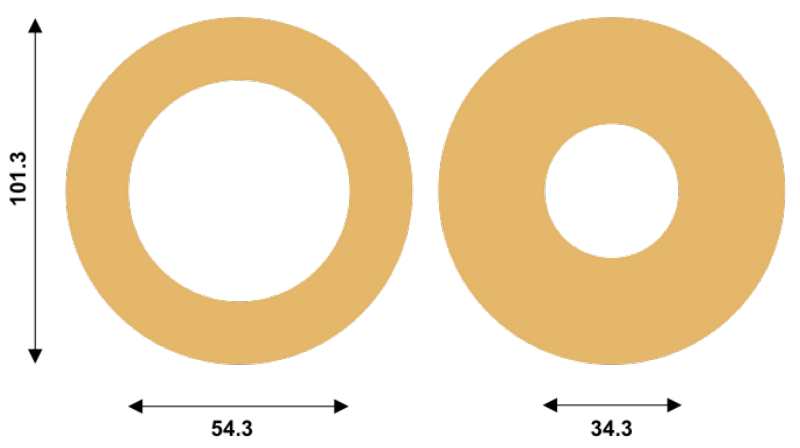

(c) Exit dam designs.

Figure 2: Features equipping the kiln: a) straight lifters (SL), b) rectangular lifters (RL) and c) exit dams.

to S5. At each section, one TC is embedded and measures the bulk temperature, Ts; the 3 remaining TC are placed in the gas phase and their measurements are averaged to yield the gas temperature Tg. An additional set of $16 \mathrm{~K}$-type insulated TC $3 \mathrm{~mm}$ in diameter are used to measure temperatures at the outer wall. As shown in Figure 3, they are inserted through the kiln insulation and placed around the outer wall in a series of 4 sections, S1 to S4 along the kiln. The average of the temperatures measured at a given section yields the wall temperature, Tw, at the corresponding position. The whole set of TC was calibrated with a tolerance of $\pm 1.5^{\circ} \mathrm{C}$ in accordance with the supplier's recommendations.

The experiments were performed at atmospheric pressure using nodular sand with an average particle size of $0.55 \mathrm{~mm}$ and without an axial forced flow of air. The thermo-physical properties of the materials used are given in Table $2\left(\right.$ at $\left.300^{\circ} \mathrm{C}\right)$. Note that the density and specific heat capacity of the sand were assumed constant, and the thermal conductivity was determined after the model by [40]. For air, the density was determined from the ideal gas law, and the specific heat capacity and conductivity were determined from [41]. The Inconel thermal properties were extracted from the manufacturer documents $[42,43]$ that provide Total Normal Emissivity on Oxidized Inconel by heating 15 min at several temperatures. The emissivity of the sand is provided by [44] and was already used by [14], who designed the pilot rotary kiln.

\subsection{Experimental procedure}

The experimental procedure developed to investigate the wall-to-solid heat transfer coefficient comprised the following four steps:

1. The operating parameters are set to the desired value: the kiln slope is adjusted to $3^{\circ}$ (same angle for all runs); rectangular, straight or no lifters are installed at the kiln tube internal wall; the measuring rod is then installed inside the kiln; the desired exit dam is fixed; the rotational speed and the feed 


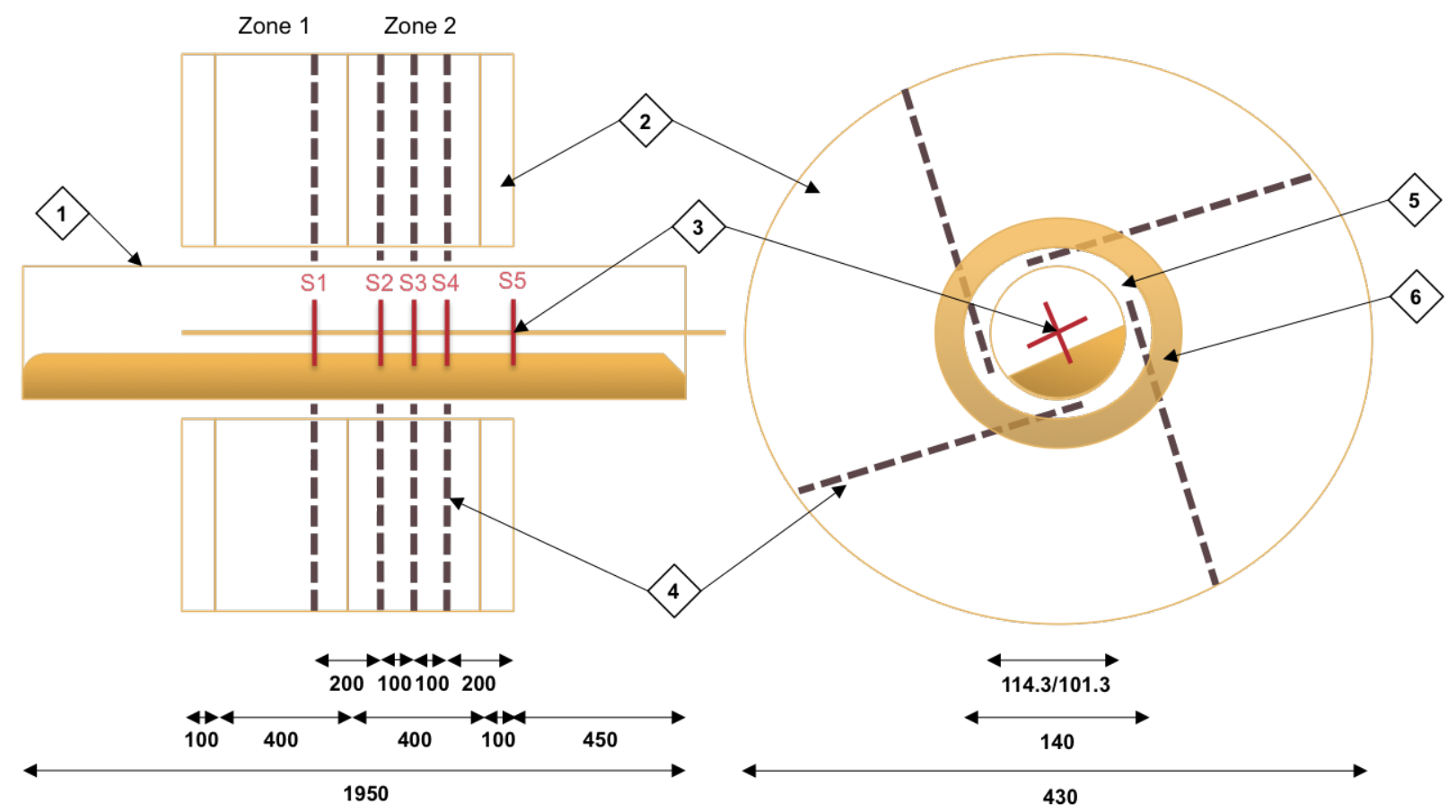

Figure 3: Layout of the experimental apparatus heating zones, longitudinal (left side) and transverse (right side) sections: (1) kiln tube, (2) insulation, (3) measuring rod with N-type thermocouples, (4) outer wall K-type thermocouples, (5) air, (6) heating resistors. The dimensions given in the drawing are in $\mathrm{mm}$.

Table 2: Thermal properties of materials at $300^{\circ} \mathrm{C}$.

\begin{tabular}{ccccc}
\hline Materials & Sand & Air & Inconel & Remarks \\
\hline$\rho\left[\mathrm{kg} \cdot \mathrm{m}^{-3}\right]$ & 1422 & 0.616 & 7950 & Density \\
$c_{p}\left[\mathrm{~J} \cdot \mathrm{kg}^{-1} \cdot \mathrm{K}^{-1}\right]$ & 835 & 1045 & 514 & Specific heat capacity \\
$\mathrm{k}\left[\mathrm{W} \cdot \mathrm{m}^{-1} \cdot \mathrm{K}^{-1}\right]$ & 0.1836 & 0.0449 & 18.75 & Thermal conductivity \\
$\varepsilon[-]$ & 0.76 & $<0.01$ & 0.9 & Emissivity \\
$\epsilon_{0}[\%]$ & 43.36 & - & - & Measured porosity \\
\hline
\end{tabular}

rate are set in the control box to the desired value. The hopper is filled and kept topped up, while the kiln is operated at room temperature until steady-state flow conditions are reached. This usually takes 2 to 4 hours. The steady state is assumed to be reached when at least three consecutive measurements of the flow rate at the kiln outlet are equal within a margin of $\pm 0.05 \mathrm{~kg} \cdot \mathrm{h}^{-1}$.

2. The temperature recording is started at an arbitrary zero time. Until the end of the run, the power supplied to the installation, the ambient temperature around the kiln, and the freeboard gas temperature at the inlet end of the kiln are measured every half hour.

3. $30 \mathrm{~min}$ after starting the recording, the temperature is adjusted on the controller and the heating source is turned on either in zone 2 or in both zones 1 and 2 .

4. When the supplied power and temperature profiles (wall, gas, and bed) are stabilized, steady state conditions are established. The thermal steady state is assumed to be reached when the temperatures and the supplied power are both stable during at least 2 consecutive half hours, respectively with variations within $2^{\circ} \mathrm{C}$ or $0.01 \mathrm{~kW}$. The logging is then stopped. The solids are discharged to assess the kiln hold up.

Examples of measured temperature profiles are given in Figures 4 and 5, when the kiln is equipped with straight lifters, rotated at a speed of $2 \mathrm{rpm}$ and heated to about $300^{\circ} \mathrm{C}$ in zone 2 and in both zones 1 and 2 (see Figure 3). It is shown that the temperatures measured at the wall rise steeply from the ambient to reach a plateau at about the given setpoint temperature. Following the heating of the kiln tube wall, the gas and the solids bulk bed temperatures rise but at a lower rate and then remain constant. Figures 4 and 
5 show that a thermal gradient may exist within the free-board gas especially between the upper and lower zones at a section of the hot kiln tube.

\section{Heat transfer}

\subsection{Heat transfer mechanisms}

Heat transfer in rotary kilns involves the exchange of energy via all the fundamental physical transfer mechanisms, i.e. conduction, convection, and radiation. The heat transfer modes can be classified in three categories, corresponding to three zones, outside, inside, and across the kiln wall.

The dominant mechanism in supplying heat to the solid bed depends on: the kiln operating conditions, notably the heating temperature, the kiln tube design (mainly its diameter) and internal fixtures, and the thermal and physical properties of the solid particles, gas and the kiln wall.

As shown in Figure 6 which represents cross-sections of directly and indirectly heated rotary kilns equipped with lifters, the following heat fluxes may occur (non-exhaustive list):

1. $\Phi_{c w-c b}$, heat transfer flux between the covered wall and the bulk bed, including conduction and radiation.

2. $\Phi_{e b-g}$, heat transfer flux between the exposed bed surface and the freeboard gas, including convection and radiation terms.

3. $\Phi_{e w-g}$, heat transfer flux between the exposed wall and the freeboard gas, including convection and radiation terms.

4. $\Phi_{e w-e b}$, heat transfer flux between the exposed bed surface and the exposed wall, only in terms of radiation.

5. $\Phi_{g-f s}$, heat transfer flux between the freeboard gas and the falling solid particles by convection and radiation for kilns equipped with lifters.

6. $S_{0}$, heat supplied by the heating system, either at the inner or outer kiln wall.

7. $\Phi_{\text {loss }}$, heat loss at the kiln wall especially to the ambient for a directly heated rotary kiln by convection and radiation.

In this study, the following heat transfer paths were taken into account to determine the wall-to-solid heat transfer coefficient: wall to solid bed, wall to gas, solid bed to gas and conduction axially through the kiln wall (within the non heated zone). Note that in the absence of temperature recordings, the solids in the gas or in the lifters are not explicitly included.

\subsection{Heat balance}

Within the heating zone(s), a control volume is chosen between two sections at which the bed, gas and wall temperatures are recorded. As the bed and gas temperature variations between the selected sections are small, usually less than $15^{\circ} \mathrm{C}$, the bed and gas temperatures are assumed uniform in the control volume. The average gas and bed temperatures between the two sections are considered. The control volume is positioned between S2 and S3 when heating both zones 1 and 2, and between S3 and S4 when heating only zone 2 (see Figure 3). The selected control volume can be regarded as a slice of the kiln tube wall; in the case of constant conductivity for steady conduction and no generation of heat, the heat balance at the wall assuming one dimensional heat conduction, convection and radiation is:

$$
\rho_{w} c_{p w} \frac{\partial T_{w}}{\partial t}=\frac{\partial}{\partial z}\left(k_{w} \frac{\partial T_{w}}{\partial z}\right)+\frac{\Phi_{w}}{\Omega_{w}}
$$

The heating of the wall is assumed uniform within the control volume, $\Omega_{w}^{c r t l}$, so that there is no axial variation in the wall temperature, thus over a period $\Delta t=t_{f}-t_{i}$, Eq.4 simplifies as:

$$
\rho_{w} c_{p w} \Omega_{w}^{c t r l} \frac{\Delta T_{w}}{\Delta t}=\Phi_{w}
$$



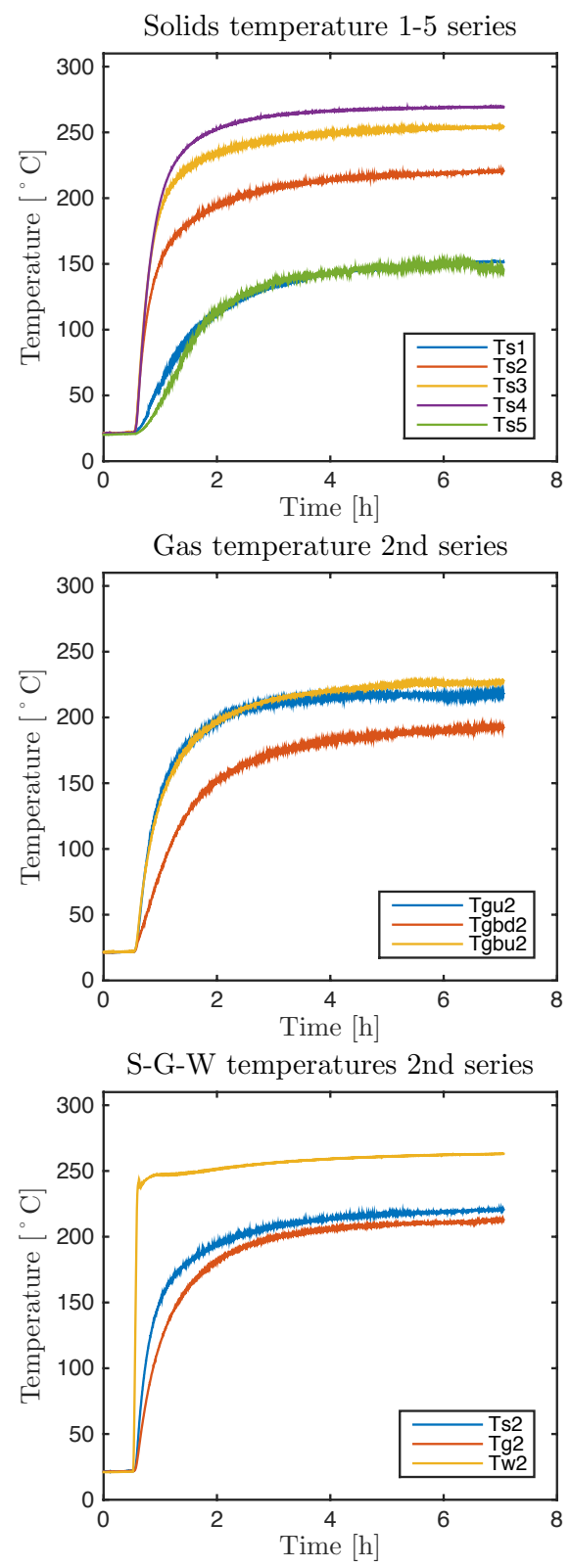
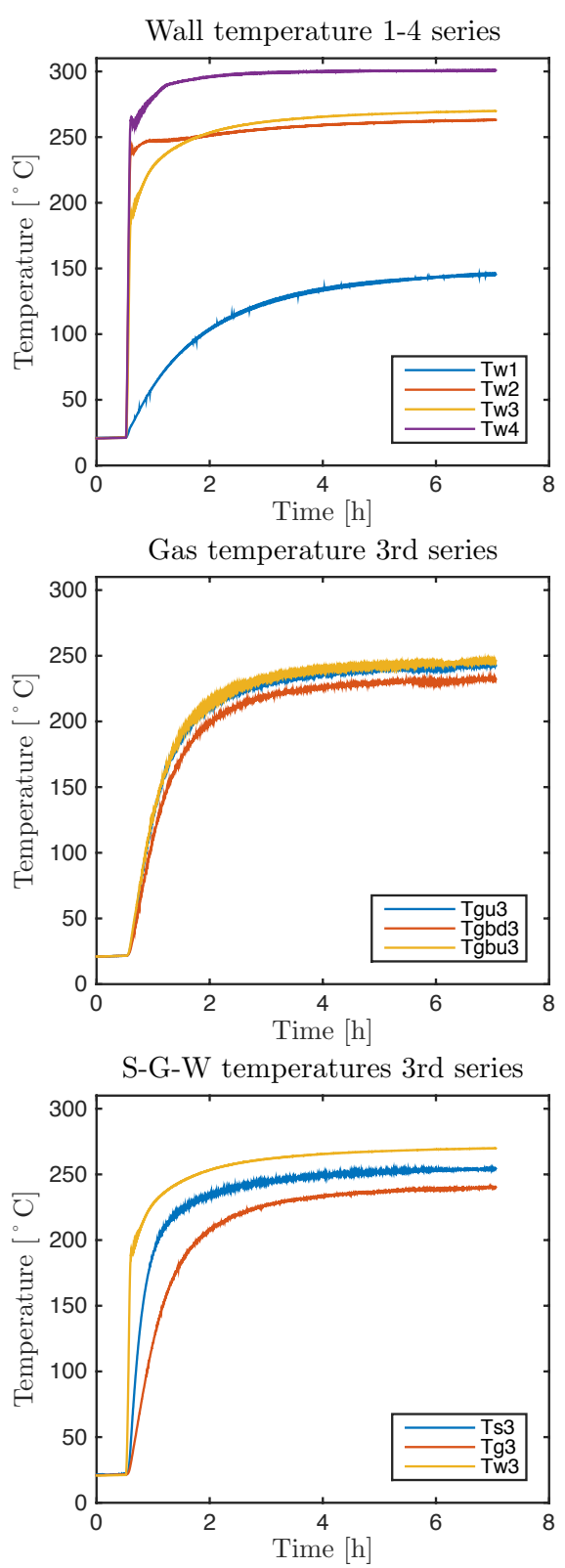
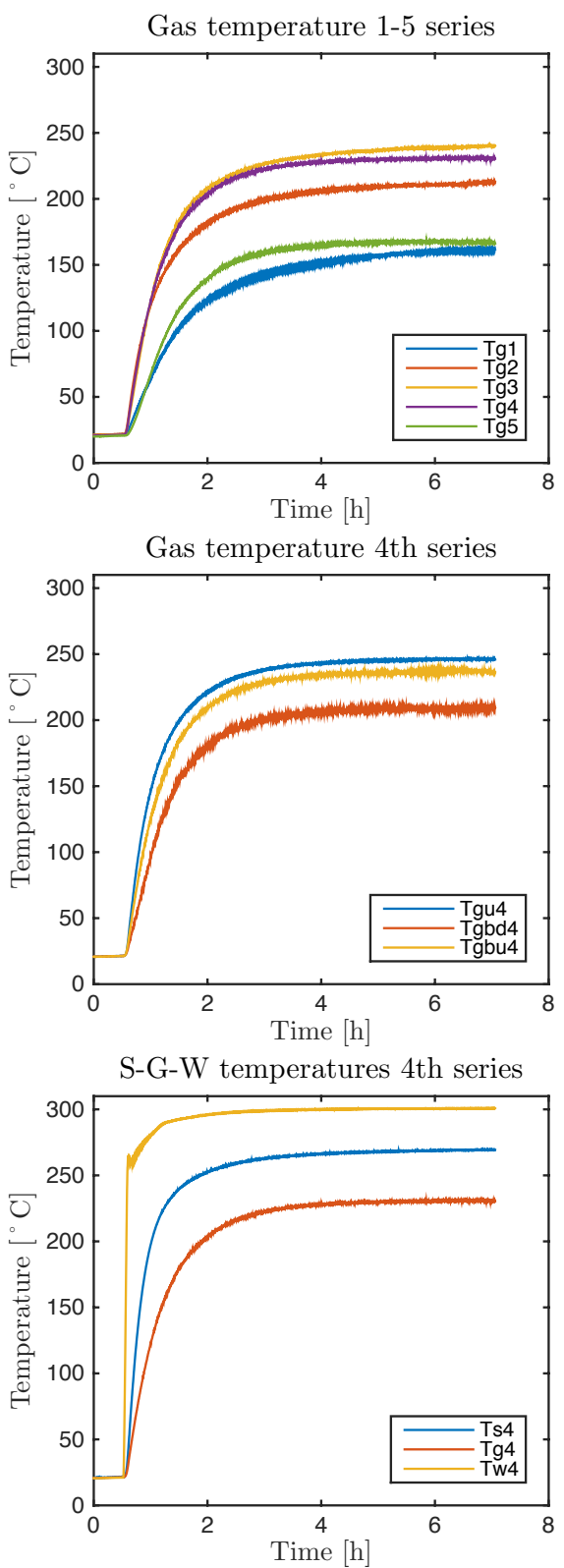

Figure 4: Experimental temperature profiles measured at the kiln outer wall, in the solids bed and in the freeboard gas. Operating conditions: $2 \mathrm{rpm}$ rotation speed, $3^{\circ}$ slope, $2.5 \mathrm{~kg} \cdot \mathrm{h}^{-1} \mathrm{MFR}, 33.5 \mathrm{~mm}$ exit dam height with straight lifters, and a setpoint temperature of $300^{\circ} \mathrm{C}$ in zone 2 . The wall and gas temperature profiles given are the average of measurements within sections S1 to S5 defined in Figure 3. $T_{s}$ is the bulk temperature; $T_{w}$ is the wall temperature; $T_{g}$ is the gas temperature; $T_{g u}$ is the temperature of gas at the top in the left side of the kiln cross section; $T_{g b d}$ is the temperature of gas at the bottom in the left side of the kiln cross section; $T_{g b u}$ is the temperature of gas at the top in the right side of the kiln cross section; the last digit indicates the axial position along the kiln. 

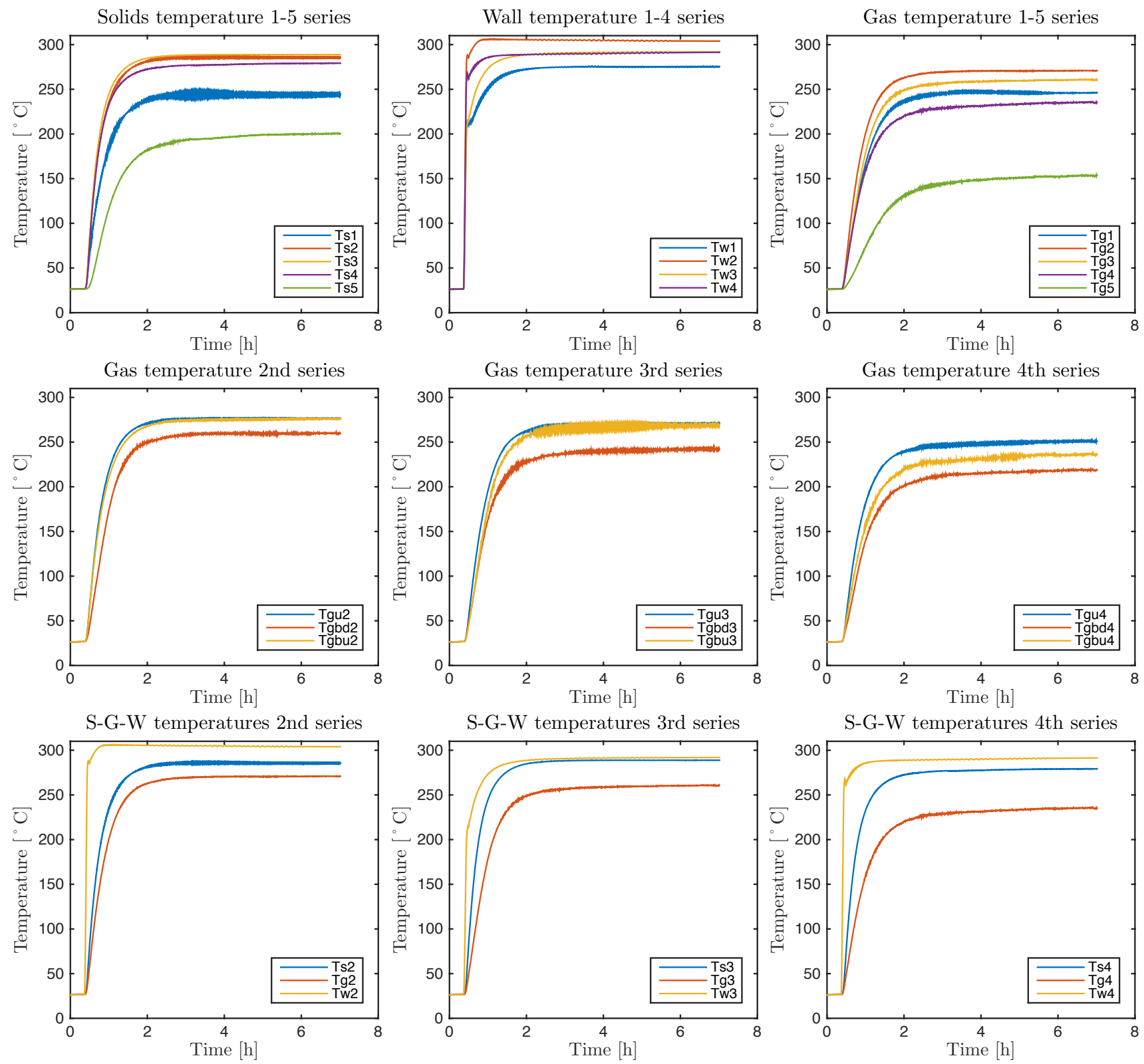

Figure 5: Experimental temperature profiles measured at the kiln outer wall, in the solids bed and in the freeboard gas. Operating conditions: $2 \mathrm{rpm}$ rotation speed, $3^{\circ}$ slope, $2.5 \mathrm{~kg} . \mathrm{h}^{-1} \mathrm{MFR}, 33.5 \mathrm{~mm}$ exit dam height with straight lifters, and a setpoint temperature of $300^{\circ} \mathrm{C}$ in zones 1 and 2 . The wall and gas temperature profiles given are the average of measurements within sections (S1-S5) defined in Figure 3. $T_{s}$ is the bulk temperature; $T_{w}$ is the wall temperature; $T_{g}$ is the gas temperature; $T_{g u}$ is the temperature of gas at the top in the left side of the kiln cross section; $T_{g b d}$ is the temperature of gas at the bottom in the left side of the kiln cross section; $T_{g b u}$ is the temperature of gas at the top in the right side of the kiln cross section; the last digit indicates the axial position along the kiln. 


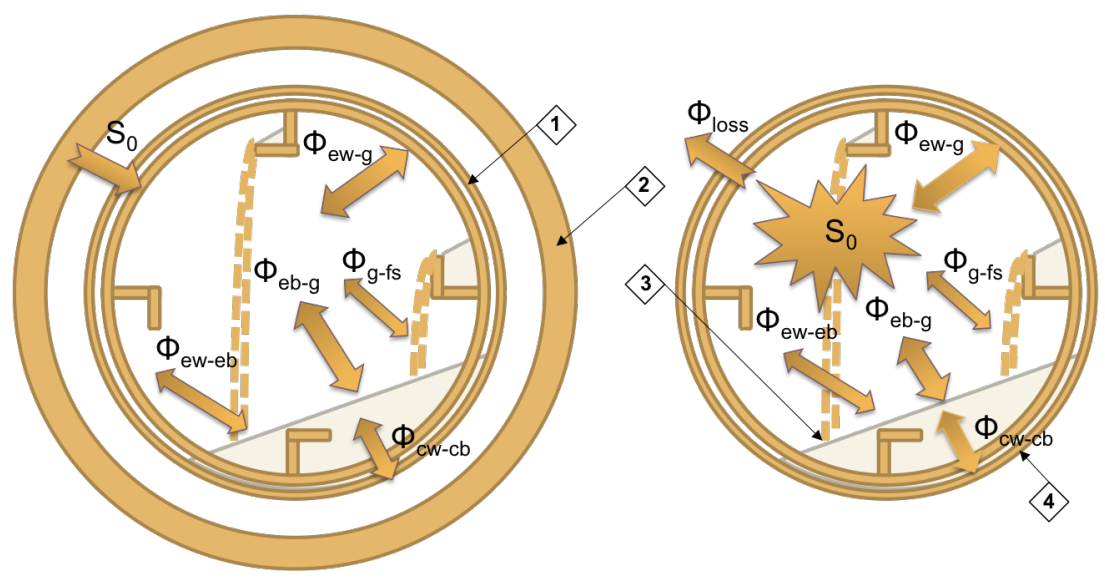

Figure 6: Heat transfer mechanisms in the cross section of indirectly (left) and directly (right) heated rotary kilns equipped with lifters. Herein: 1) exposed wall (ew), 2) heating elements, 3) exposed bed (eb), 4) covered wall $(\mathrm{cw})$, covered bed $(\mathrm{cb})$. In addition: g stands for gas, and fs for falling solids.

with $\Phi_{w}=\Phi_{e w}^{r}+\Phi_{e w-g}+\Phi_{c w-c b}+S_{0}^{\Delta t}+\Phi_{l o s s}^{\Delta t}$ where $\Phi_{e w-g}=h_{e w-g}^{c v} A_{e w} L M T D_{e w-g}$ and $\Phi_{c w-c b}=$ $h_{c w-c b} A_{c w} L M T D_{c w-c b}$

Similar to heat-exchanger problems, the logarithmic mean temperature differences (LMTD) are defined as follows:

$$
L M T D_{e w-g}=\frac{\left(T_{g}^{i}-T_{w}^{f}\right)-\left(T_{g}^{f}-T_{w}^{i}\right)}{\ln \left(\frac{\left(T_{g}^{i}-T_{w}^{f}\right)}{\left(T_{g}^{f}-T_{w}^{i}\right)}\right)}, L M T D_{c w-c b}=\frac{\left(T_{b}^{i}-T_{w}^{f}\right)-\left(T_{b}^{f}-T_{w}^{i}\right)}{\ln \left(\frac{\left(T_{b}^{i}-T_{w}^{f}\right)}{\left(T_{b}^{f}-T_{w}^{i}\right)}\right)}
$$

The wall-to-solid heat transfer coefficient was then determined with the use of the supplied power measured and temperature recordings through:

$$
h_{c w-c b}=\frac{\left(\rho_{w} c_{p w} \Omega_{w}^{c t r l} \Delta T_{w} / \Delta t\right)-\left(\Phi_{e w}^{r}+h_{c w-g}^{c v} A_{e w} L M T D_{e w-g}+S_{0}^{\Delta t}+\Phi_{l o s s}^{\Delta t}\right)}{A_{c w} L M T D_{c w-c b}}
$$

The supplied power measured, $\Phi_{k i l n}$, includes the power delivered to the 2 motors driving the kiln tube and the screw feeder rotationally. These contributions are determined from measurements performed before starting the heating. The effective heating power at the heated zone(s), $\Phi_{\text {eff }}$ can then be deduced. Assuming that power is uniformly and totally transferred to the wall by the resistors through radiation over the length, $l_{Z o n e}$, the heating power within the control volume of length, $l_{c t r l}$, is $S_{0}=\Phi_{\text {eff }} \frac{l_{c t r l}}{l_{\text {Zone }}}$.

The losses are determined differently depending on whether both zones 1 and 2 are heated or only zone 2 is heated. In the former case, the heat losses include the heating of the measuring rod and the heat losses through the insulation. The temperature of the rod is assumed to be virtually equal to the gas temperature for the calculation. Hence, $\Phi_{\text {loss }}=\rho_{\text {rod }} c_{\text {prod }} \Omega_{\text {rod }}^{c t r l} \frac{\Delta T_{\text {rod }}}{\Delta t}+\phi_{\text {ins }} l_{c t r l}$; note that the rod is of the same material as the kiln tube and lifters. In the latter case, the heat losses include the heat transfer within the wall by conduction toward the insulated zone 1 as well as the heat losses through the insulation. Indeed it can be seen in Figure 4 that the wall temperature also increases at section S1 in zone 1. For the calculation the losses are determined up to S1 using the temperature measured at that section giving:

$$
\Phi_{\text {loss }}=\rho_{\text {rod }} c_{\text {prod }} \Omega_{\text {rod }}^{c t r l} \frac{\Delta T_{\text {rod }}}{\Delta t}+\rho_{w} c_{p w} \Omega_{w}^{S 1-Z o n e 2} \frac{l_{\text {ctrl }}}{l_{\text {Zone }}} \frac{\Delta T_{w}}{\Delta t}+\phi_{\text {ins }} l_{\text {ctrl }}
$$

The heat losses through the insulation covering the heating elements were estimated for each heating temperature. When heating at 100,300 and $500^{\circ} \mathrm{C}$, the heat losses through the insulation per unit length, $\phi_{\text {ins }}$, were respectively estimated to be about 50, 195 and $390 \mathrm{~W} \cdot \mathrm{m}^{-1}$; details of the calculations are given in A.

\subsection{Convection and radiation modeling}

\subsubsection{Convective heat transfer}

Convective heat transfer may occur between the freeboard gas and the boundaries limiting the gas volume. As there is no axial forced flow of the gas, the heat transfer coefficient between the exposed wall and the 
gas can be estimated with the use of the correlation obtained from a preliminary analysis ([39] chap. 6):

$$
N u_{e w-g}=\frac{h_{e w-g} D_{e}}{k_{g}}=0.1085 \operatorname{Re}_{\omega}^{0.0275} \operatorname{Pr}^{-0.4839}\left(\frac{l_{g}}{D}\right)^{-1.9284}\left(10^{-10} \frac{c_{p g} \rho_{g} T_{g}^{\infty}}{\omega \mu_{g}}\right)^{-0.2208}
$$

herein, the Nusselt number is based on the equivalent diameter,

$$
D_{e}=\frac{D(2 \pi-\psi+\sin \psi)}{2(\pi-\psi / 2+\sin \psi / 2)}
$$

which is a function of the filling angle (see Figure 7). Within the range of variation of the operating parameters set for the experiments, the application of Eq. 6 yields coefficients higher than, or about, $10^{-2} \mathrm{~W} \cdot \mathrm{m}^{-2} \cdot \mathrm{K}^{-1}$.
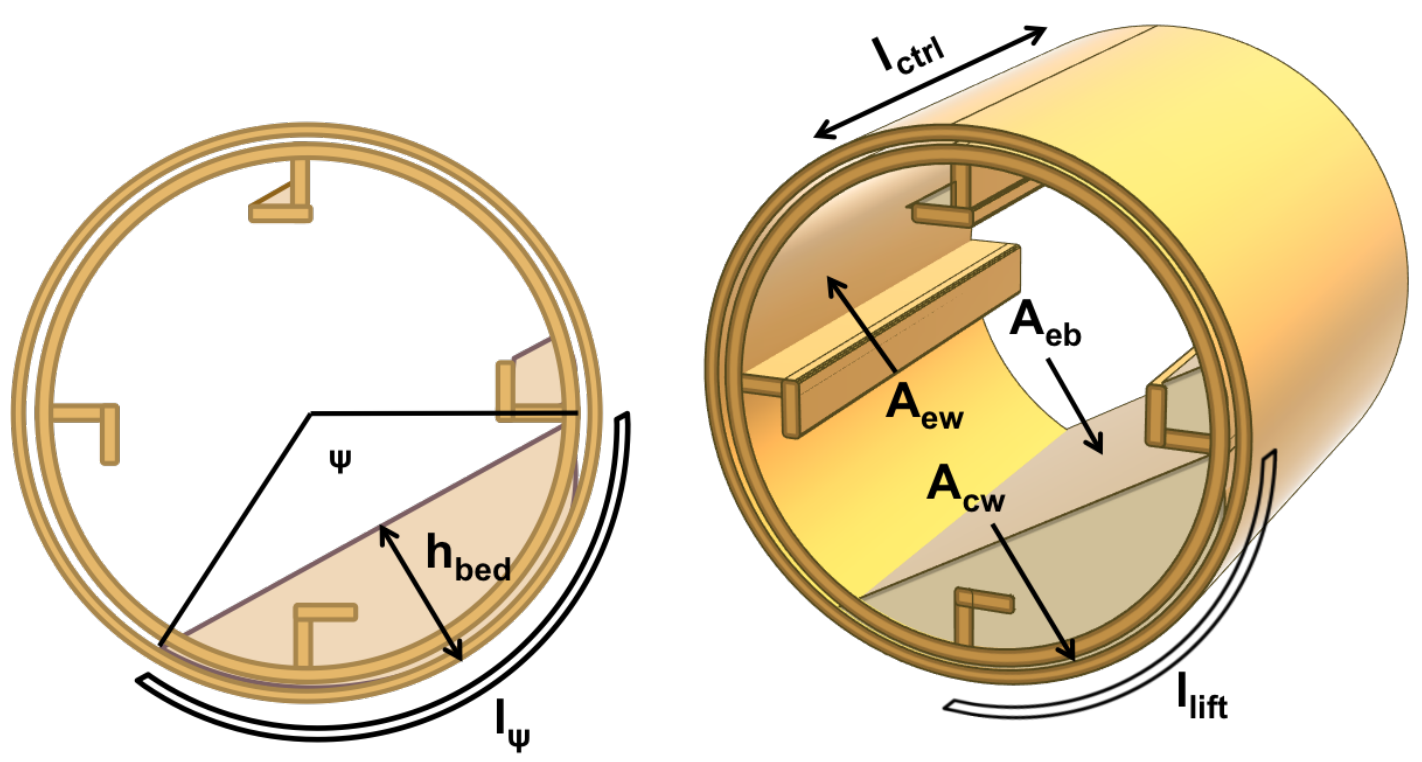

Figure 7: Kiln sections with nomenclature of the heat transfer areas, the bed depth and the filling angle.

\subsubsection{Radiation heat transfer}

To calculate the heat fluxes exchanged by radiation, [45] developed an electrical analogy for a gray body where the following two quantities were defined:

1. Irradiance, $E$, the flux of energy that irradiates the surface, per unit area and per unit time.

2. Radiosity, $J$, the total radiation energy streaming from the surface, per unit area per unit time. The radiosity is the summation of the irradiated energy that is reflected and the radiation emitted by the surface as follows:

$$
J=\varepsilon \sigma T^{4}+(1-\varepsilon) E
$$

The net heat flux leaving any particular surface can be written as the difference between $J$ and $E$, giving with Eq.7:

$$
\frac{\phi}{A}=J-E=\frac{\varepsilon}{1-\varepsilon}\left(\sigma T^{4}-J\right)
$$

Considering a surface $i$ reflecting on $n$ surfaces referred to as $j$, it is possible to write [46]:

$$
J_{i}=\varepsilon_{i} \sigma T_{i}^{4}+\left(1-\varepsilon_{i}\right) \sum_{j=1}^{n} F_{i, j} \tau_{g} J_{j}+\left(1-\varepsilon_{i}\right) \varepsilon_{g} \sigma T_{g}^{4}
$$

where $F_{i, j}$ is the view factor between the surface areas $A_{i}$ and $A_{j}$. The view factor (or shape factor) is a purely geometrical parameter that accounts for the effects of orientation on radiation between surfaces. The 
view factor ranges between zero and one. Gorog et al. [47] defined the view factors for the one-zone wall model as follows: $F_{b b}=0, F_{b w}=1, F_{w b}=\frac{A_{e b}}{A_{e w}}, F_{w w}=1-F_{w b} \cdot \tau_{g}=1-\varepsilon_{g}$ is the fraction of irradiation transmitted through the gas. Eq.9 can be written as a system of two unknowns, $J_{b}$ and $J_{w}$ :

$$
\left[\begin{array}{cc}
Z_{b b} & Z_{b w} \\
Z_{w b} & Z_{w w}
\end{array}\right]\left[\begin{array}{c}
J_{b} \\
J_{w}
\end{array}\right]=\left[\begin{array}{c}
B_{b} \\
B_{w}
\end{array}\right]
$$

with: $Z_{b b}=1-\left(1-\varepsilon_{b}\right) F_{b b}\left(1-\varepsilon_{g}\right)$,

$Z_{b w}=-\left(1-\varepsilon_{b}\right) F_{b w}\left(1-\varepsilon_{g}\right)$,

$Z_{w b}=-\left(1-\varepsilon_{w}\right) F_{w b}\left(1-\varepsilon_{g}\right)$,

$Z_{w w}=1-\left(1-\varepsilon_{w}\right) F_{w w}\left(1-\varepsilon_{g}\right)$,

$B_{b}=\varepsilon_{b} \sigma T_{b}^{4}+\left(1-\varepsilon_{b}\right) \varepsilon_{g} \sigma T_{g}^{4}$,

and $B_{w}=\varepsilon_{w} \sigma T_{w}^{4}+\left(1-\varepsilon_{w}\right) \varepsilon_{g} \sigma T_{g}^{4}$.

When using Eq.8, the radiant heat transfer flux from the bed surface is expressed as: $\Phi_{b}^{r}=\frac{\varepsilon_{b}}{1-\varepsilon_{b}}\left(\sigma T_{b}^{4}-J_{b}\right) A_{e b}$

The radiant heat transfer flux from the exposed wall, with the use of Eq.8, is given by: $\Phi_{w}^{r}=\frac{\varepsilon_{w}}{1-\varepsilon_{w}}\left(\sigma T_{w}^{4}-J_{w}\right) A_{e w}$

Solving Eq.10 allows the determination of both radiosities $J_{b}$ and $J_{w}$, and thus the estimation of the corresponding heat transfer flux.

\subsection{Estimation of heat transfer areas}

An accurate definition of the heat transfer areas is essential for the calculation of the heat fluxes (convective or radiative) on the one hand and the wall-to-solid heat transfer coefficient on the other hand. Knowledge of the bed depth, $h_{b e d}$, or the kiln filling angle, $\psi$, is required for the determination of the main heat transfer areas, namely, $A_{e w}$, the interfacial area between the exposed wall (including lifters) and the free-board gas, $A_{e b}$, the interfacial area between the exposed wall and the free-board gas, and $A_{c w}$ the interfacial area between the covered wall (including lifters) and the bed of solid particles, within the control volume of length $l_{c t r l}$. Figure 7 illustrates the bed depth, $h_{b e d}$, and the kiln filling angle, $\psi$, as well as the main heat transfer areas presented above.

The bed depth is assumed almost flat along the kiln, even though this may not be the case at the kiln ends. Under this assumption, the filling angle is determined from the measured kiln hold-up as follows:

$$
\frac{H U}{\rho_{b}}=\Omega_{b}^{k i l n}=R^{2} \frac{\psi-\sin \psi}{2} L
$$

With the use of the filling angle, the bed depth is then determined as follows:

$$
h_{\text {bed }}=R\left(1-\cos \frac{\psi}{2}\right)
$$

Bed depth profile measurements were performed for varying experimental conditions without lifters. These measurements were intended primarily to assess the experimental bed depth within the heating zone 2 , where the control volume for the calculations is located. Therefore the measurements of bed depth were mainly located between sections S1 and S5 (see Figure 3). For this purpose, a measuring rod equipped with 10 thin stems $50 \mathrm{~mm}$ in length and $5 \mathrm{~mm}$ in diameter, and rotating with the kiln was used. The stems were coated with glue, so that the bed depth could be assessed by measuring the height of hooked particles once steady flow conditions had been achieved. Details about the set up and the experimental procedures are given in B. Figure 16 displays the resulting bed depth profiles in zone 2 determined either by experimental measurements or with the use of Eqs. 11 and 12. As can be seen in Figure 16, except in one case, the experimental bed depth measurements and the calculated bed depth agree well. It can also be mentioned that the bed depth increases with the mass flow rate or the exit dam height; these variations can be related to those of the hold-up with the operating parameters. The hold-up and the bed depth are linked, as suggested by Eqs.11 and 12: higher hold-up may result in higher bed depth. These two equations were then used to determine the bed depth and filling angle with the use of measured hold-up.

The identified heat transfer areas can then be determined as follows:

$$
\begin{aligned}
& A_{\text {ew }}=\alpha\left(R(2 \pi-\psi)+2 d_{\text {eff }}^{e w} n_{\text {lift }}^{\text {ew }}\right) l_{c t r l}, \quad n_{\text {lift }}^{\text {ew }}=n_{\text {lift }}^{\text {total }}-\frac{l_{\psi}}{l_{\text {lift }}} \\
& A_{\text {eb }}=\beta\left(2 \sqrt{h_{\text {bed }} D-h_{\text {bed }}^{2}}\right) l_{c t r l},
\end{aligned}
$$




$$
A_{c w}=\quad \gamma\left(R \psi+2 d_{\text {eff }}^{c w} n_{\text {lift }}^{c w}\right) l_{\text {ctrl }}, \quad n_{\text {lift }}^{c w}=\frac{l_{\psi}}{l_{\text {lift }}}
$$

The coefficients $\alpha, \beta$ and $\gamma$ account for the smoothness of the surfaces. The internal kiln tube wall and the lifters can be considered as smooth surfaces, but this may not be the case for the surfaces at the exposed bed of solids or the contact surface with the wall at the bottom of the bed. Therefore the coefficient $\alpha$ was set to 1 , and measurements were performed to determine the coefficients $\beta$ and $\gamma$.

Using the AltiSurf 520 system, 3D micro-topography was performed over planar surfaces of solids 10 $\mathrm{mm}$ by $5 \mathrm{~mm}$ (3 replicates). The profilometric measurements show that the heights of peaks and valleys along the surface are less than $15 \%$ of the particle diameter on average, so that the surface at the exposed bed can be considered plane, and $\beta$ can be taken as 1 . Finally, $\gamma$, which accounts for the gas gap between the wall and solid particles, was determined by considering the percentage area filled with solid particles above the determined zero altitude; it was estimated to be about $84.83 \% \pm 8.76$. This value is of the order of $80 \%$, as given in the previous literature [29].

Both surface areas, $A_{e w}$ and $A_{c w}$, account respectively for the fraction of the kiln wall circumference including lifters that is exposed or covered, within the control volume of length $l_{c t r l}$. The number of lifters within the covered wall, $n_{\text {lift }}^{c w}$, was estimated by the ratio of the arc length of the covered wall, $l \psi$ (see Figure 7 ), to the arc length between two consecutive lifters, $l_{\text {lift }}$ (see Figure 7 ). The number of lifters, $n_{\text {lift }}^{e w}$, at the exposed wall was determined by subtracting $n_{\text {lift }}^{c w}$ from the total number of lifters, $n_{\text {lift }}^{\text {total }}$. Regarding the lifters, instead of their actual length, the effective length for the heat transfer, $d_{e f f}$, was used. An expression for the lifter effective length was presented in a preliminary analysis ([39] chap. 6).

\section{Results and discussion}

The evaluation of the wall-to-solid (w-t-s) heat transfer coefficient was achieved over a period $\Delta t$. This period is imposed by the time required for the measurement of the electrical power supplied to the unit. The measurement was performed using a multifunction meter, which displays the measured power every 30 min. The coefficient was then evaluated every half hour over the length of the run from the temperature profiles and the supplied power.

\subsection{Experimental wall-to-solid heat transfer coefficient}

\subsubsection{Time variation of the coefficient}

Figure 8 represents the time variation of the w-t-s heat transfer coefficient for both runs, of which the experimental temperature profiles are shown in Figures 4 and 5. The experimental conditions in these experiments were similar except for the heating zone. For both, the results show that the coefficient increases rapidly during the first two hours and then remains virtually constant, similar to the temperature profiles. One may expect very similar trends of the profiles, but there are some discrepancies between the two profiles with higher values of the coefficient for the experiment heating both zones 1 and 2 . The difference observed can possibly be due to the hypothesis made while taking into account the losses. However the calculated error bars of the coefficients of these runs are mostly overlapping.

Further details about the calculation of the uncertainties are given in the C. For the global analysis of the results, the coefficient was averaged over the last 4 values determined, i.e. the last two hours of each run. For example, as given in Figure 8, the averaged w-t-s heat transfer coefficients were $293 \pm 32 \mathrm{~W} \cdot \mathrm{m}^{-2} \cdot \mathrm{K}^{-1}$ and $249 \pm 29 \mathrm{~W} \cdot \mathrm{m}^{-2} \cdot \mathrm{K}^{-1}$, respectively when heating the kiln in zone 2 and in both zones 1 and 2 . The experimental results are summarized in Table 3.

\subsubsection{Effect of convection and radiation}

Convective heat transfer has been mostly considered in the literature for the case of directly heated kilns with turbulent gas flow conditions. Although the order of magnitude for the wall-to-gas (w-t-g) heat transfer coefficient, in the case of no axial forced flow of the gas, determined to be above about $10^{-2} \mathrm{~W} \cdot \mathrm{m}^{-2} \cdot \mathrm{K}^{-1}$ may seem quite small, it must be mentioned that while using a correlation recommended by [48], [37] found a w-t-g heat transfer coefficient about $1 \mathrm{~W} \cdot \mathrm{m}^{-2} \cdot \mathrm{K}^{-1}$ for a low gas flow within an industrial kiln with a length-to-diameter ratio of 6.6 . 


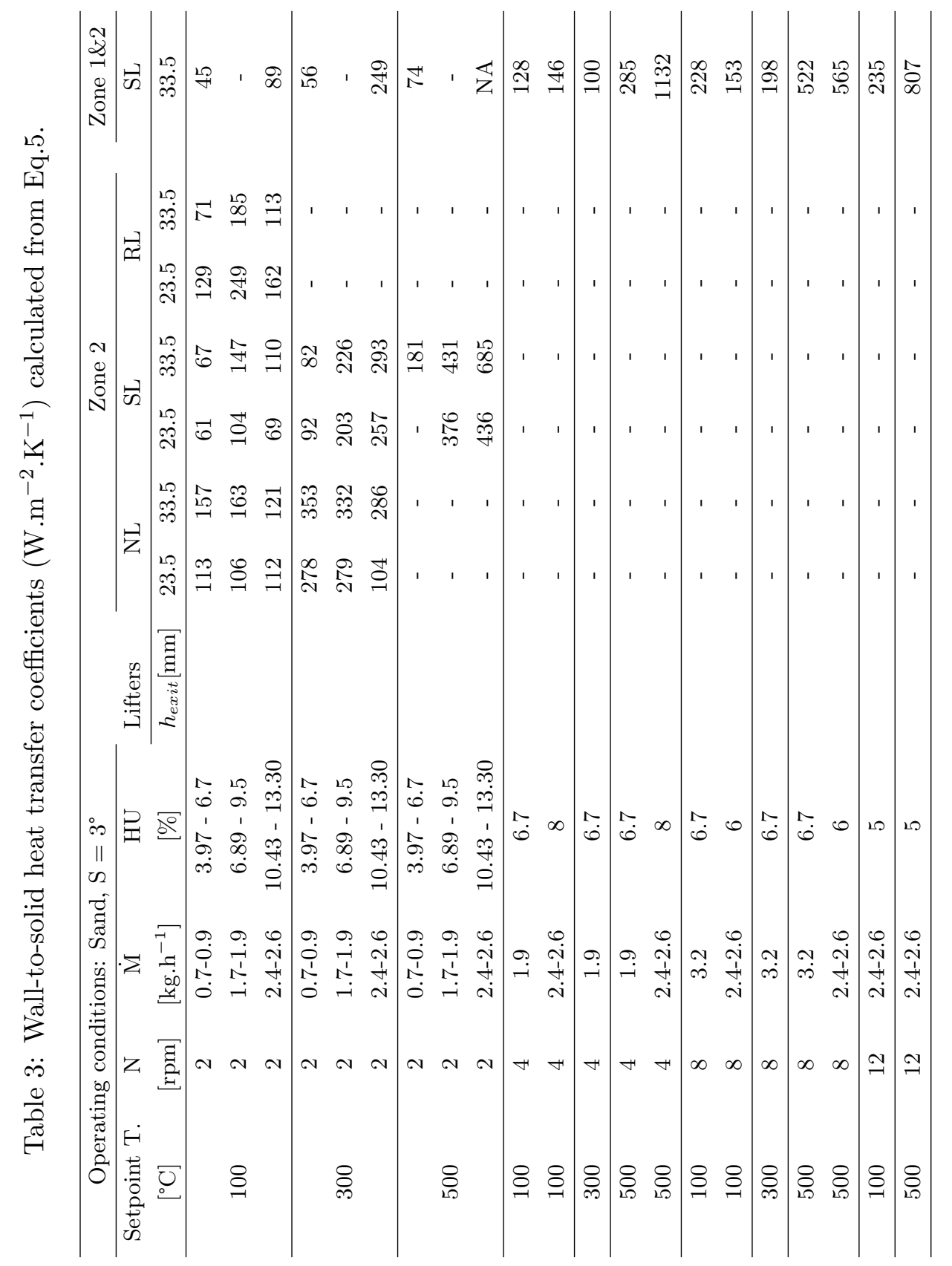




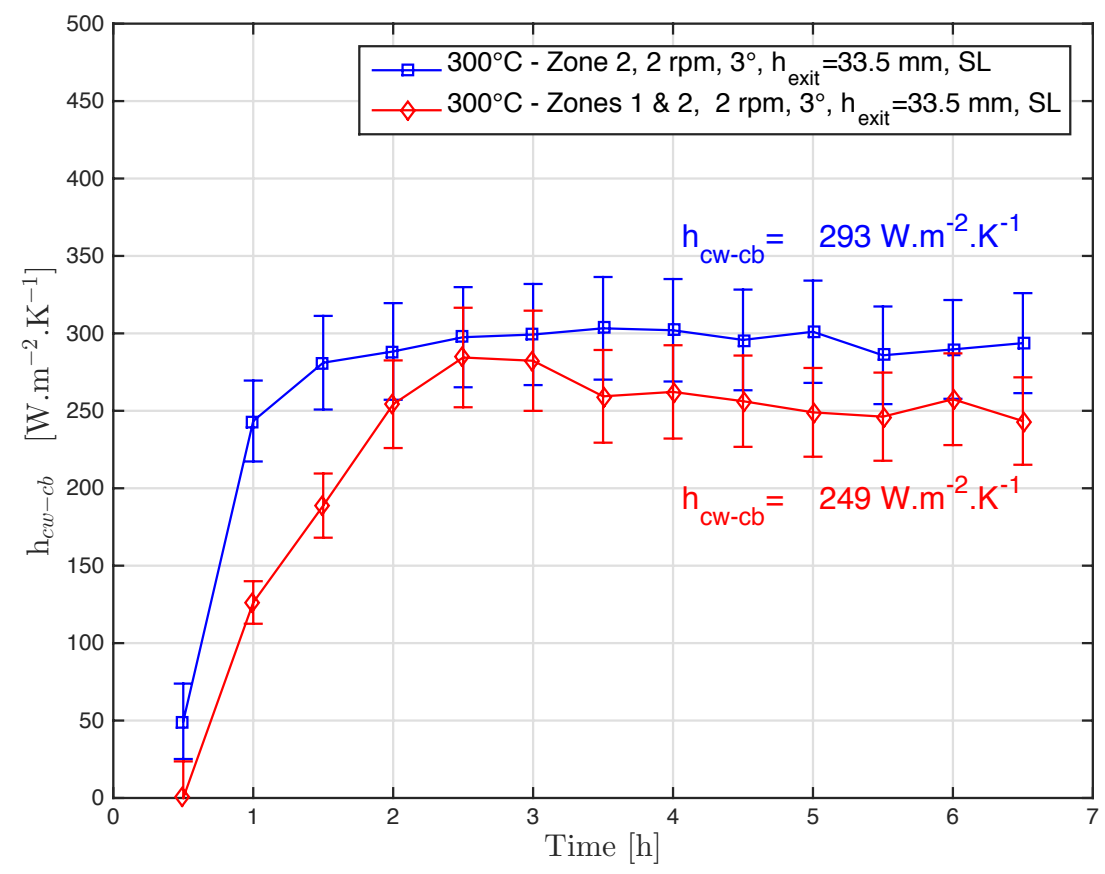

Figure 8: Time variation of the wall-to-solid heat transfer coefficient for both runs represented in Figures 4 and 5 .

Radiation within the kiln may be very high and can dominate the heat transfer at high operating temperatures. [32] specified that, in general, at temperatures below $300-400^{\circ} \mathrm{C}$, the contribution of radiation is negligible, around $700-900^{\circ} \mathrm{C}$, radiative and convective heat transfers have the same order of magnitude, and above $1000^{\circ} \mathrm{C}$ radiative transfer becomes dominant. In this study, experiments were conducted at low to medium temperatures: $100-500^{\circ} \mathrm{C}$.

Figures 9 shows the variation of the w-t-s heat transfer coefficient when assuming neither convection nor radiation, then only convection and finally both convection and radiation, at 100,300 and $500^{\circ} \mathrm{C}$ setpoint temperatures. The results show that the convective heat transfer has no significant effect on the calculations of the w-t-s heat transfer coefficient, since whatever the setpoint temperature, the error introduced by making the assumption of negligible convection is very small, about $0.05 \%$, whereas the effect of the radiative heat exchange at the wall on the heat transfer coefficient grows as the setpoint temperature increases. Had the radiation (and convection) been neglected, the calculations might have led to an overestimation of the heat transfer coefficient by about $7 \%$ at $100^{\circ} \mathrm{C}, 13 \%$ at $300^{\circ} \mathrm{C}$ and $16 \%$ at $500^{\circ} \mathrm{C}$ on average.

\subsubsection{Effect of operating parameters}

The influence of the operating parameters, namely the mass flow rate, the exit dam height and the lifter hold-up capacity on the w-t-s heat transfer coefficient were analyzed with the use of the filling degree, as the filling degree has been found to increase with these operating parameters [49, 50, 51]. Figure 10 shows the variation of the w-t-s heat transfer coefficient with the filling degree following a variation of the mass flow rate, the exit dam height and the lifter hold-up capacity. The results do not display a clear trend upward or downward contrary to what was observed in a preliminary analysis. However these results confirm a previous finding showing that the heat transfer can be enhanced depending on the lifter profile being used. Higher values of the heat transfer coefficient are obtained when using rectangular lifters while the coefficient is lower in the case of runs without lifters and even lower when using straight lifters. This suggests the existence of a critical lifter design that maximizes heat transfer.

The effect of the rotational speed on the w-t-s heat transfer coefficient is shown in Figure 11. The rotational speed was varied while keeping a constant flow rate on the one hand and then a constant filling degree on the other hand. Except for the results obtained at a setpoint temperature of $500^{\circ} \mathrm{C}$ when varying the rotational speed at a constant flow rate, the coefficient increased with the rotational speed. A similar trend was found in a preliminary analysis ([39] chap. 6). Hence, the rotational speed which promotes the mixing effect within the rotary kiln as well as the temperature set point can be identified as possible 
a) $100^{\circ} \mathrm{C}$ - Zone 2

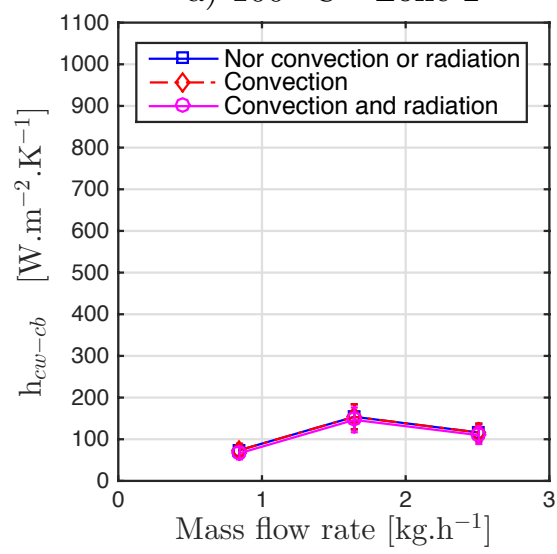

b) $300^{\circ} \mathrm{C}$ - Zone 2

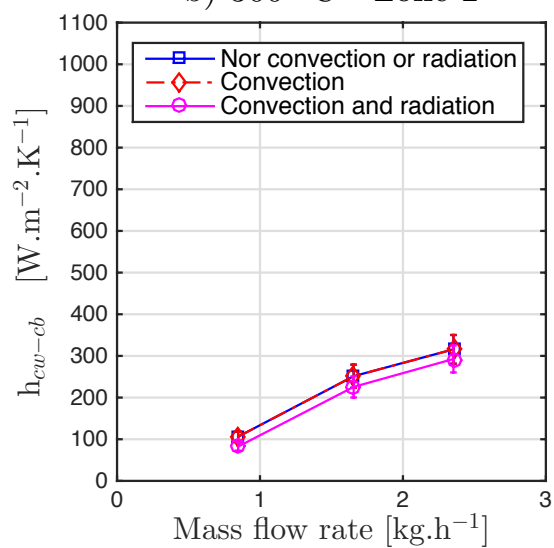

c) $500^{\circ} \mathrm{C}$ - Zone 2

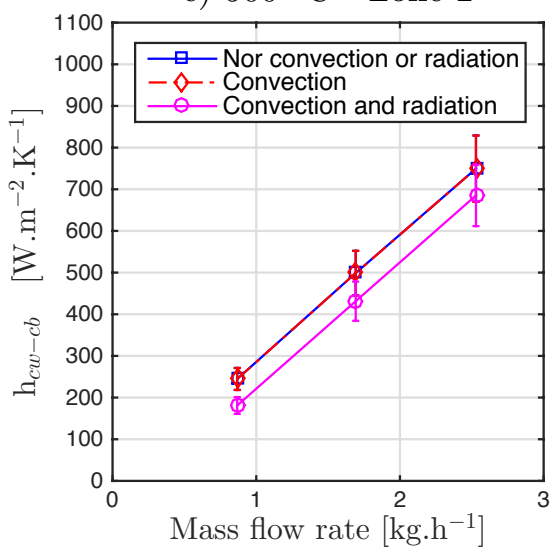

Figure 9: Effect of the convection and radiation heat transfers on the calculated value of the wall-to-solid heat transfer coefficient at different setpoint temperatures in zone 2: a) $100^{\circ} \mathrm{C}$, b) $300^{\circ} \mathrm{C}$ and c) $500^{\circ} \mathrm{C}$, while varying the mass flow rate, and operating at a rotational speed of $2 \mathrm{rpm}$, a kiln slope of $3^{\circ}$, an exit dam height of $33.5 \mathrm{~mm}$ and with straight lifters.

a) $100{ }^{\circ} \mathrm{C}$ - Zone 2

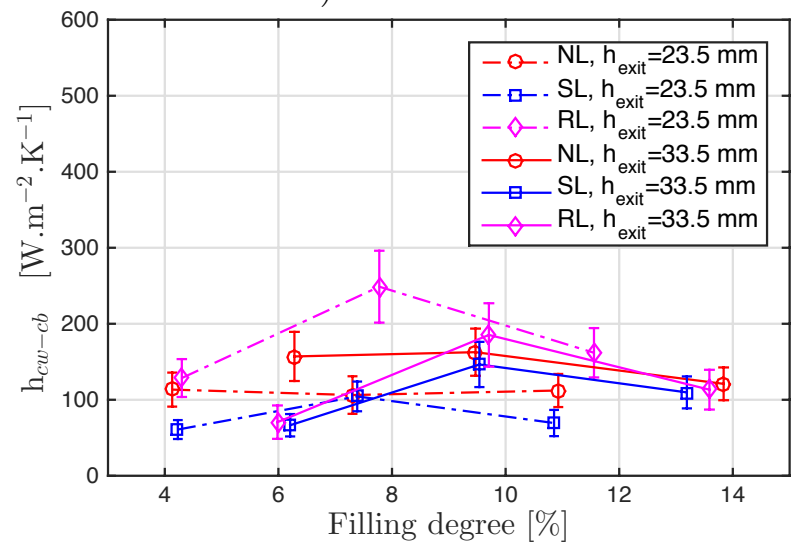

b) $300{ }^{\circ} \mathrm{C}$ - Zone 2

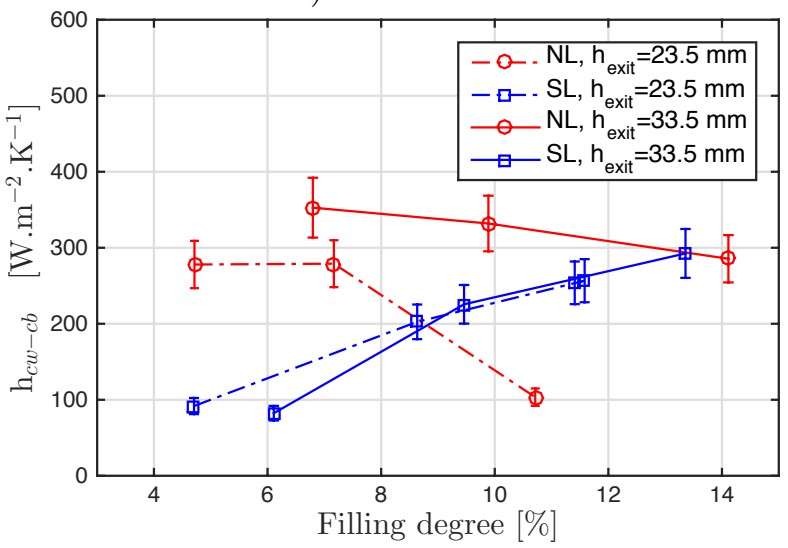

Figure 10: Variation of the wall-to-solid heat transfer coefficient with the filling degree at different setpoint temperatures in zone 2 : a) $100^{\circ} \mathrm{C}$ and b) $300^{\circ} \mathrm{C}$, while varying the lifters, the exit dam and the mass flow rate, and operating at a rotational speed of $2 \mathrm{rpm}$, a kiln slope of $3^{\circ}$.

parameters that might be optimized in order to enhance the heat transfer, while also taking into account the whole set of operating parameters.

\subsection{Modeling of the wall-to-solid heat transfer coefficient}

Modeling the wall-to-solid heat transfer is a complex task in particular due to the strong non-linearity of the radiation heat transfer. As presented below, the wall-to-solid heat transfer was correlated following a dimensional analysis. The experimental results were then compared with the predictions of models from the literature.

\subsubsection{Model}

The main purpose of this model is to come up with a prediction of the heat transfer coefficient between wall and solid particles, to be used in a global model of rotary kilns. Within a heated zone, this model takes into account the kiln design, in particular the internal diameter, the bulk thermal properties, and the operating conditions, namely rotational speed, presence of lifters, filling degree and temperature set at the wall. Considering the Buckingham (П) theorem, the coefficient is expressed in terms of dimensionless numbers as follows [52]: 
a) Constant flow rate: $2.6 \mathrm{~kg} \cdot \mathrm{h}^{-1}$

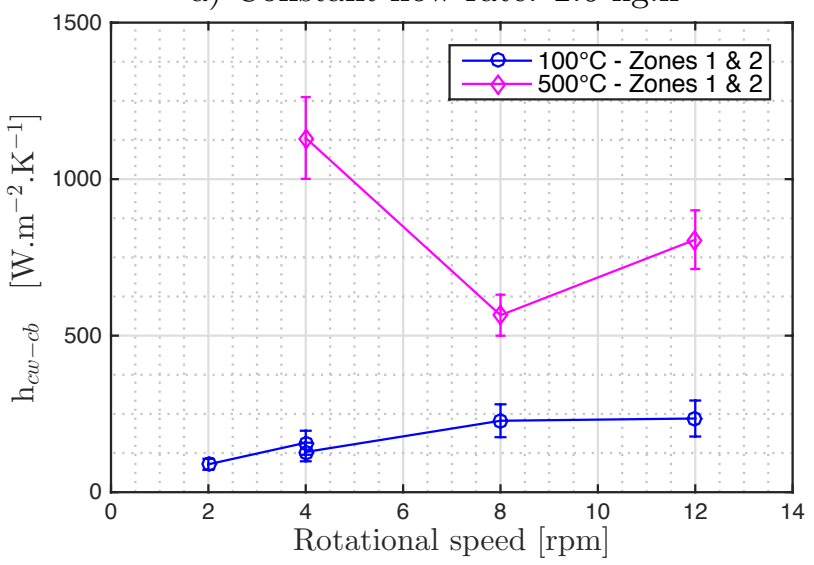

b) Constant filling degree: $6.7 \%$

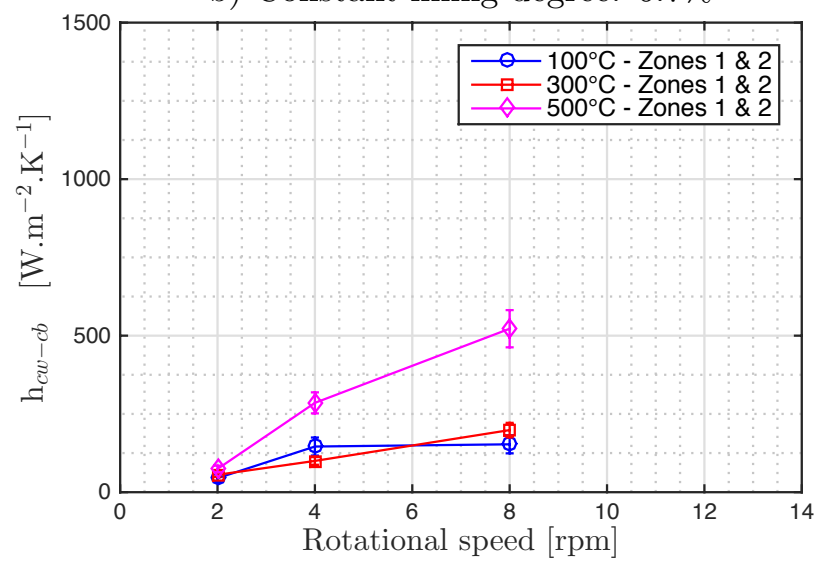

Figure 11: Variation of the wall-to-solid heat transfer coefficient with the kiln rotational speed at a) constant flow rate and b) constant filling degree, while heating in both zones 1 and 2 , and operating at a slope of $3^{\circ}$, with straight lifters and an exit dam (33.5 mm in height).

Table 4: Estimated parameters for the model proposed for the wall-to-solid heat transfer coefficient, with associated confidence intervals.

\begin{tabular}{lrrr}
\hline \multirow{2}{*}{$\begin{array}{c}\text { Model } \\
\text { parameters }\end{array}$} & \multicolumn{2}{c}{ Confid. intervals } \\
\cline { 3 - 4 }$K$ & $\mathbf{2 . 1 3 7 1}$ & -3.8809 & 8.1551 \\
\hline$\alpha$ & $\mathbf{0 . 4 5 3 1}$ & 0.2336 & 0.6725 \\
\hline$\beta$ & $\mathbf{- 0 . 3 5 0 7}$ & -1.2654 & 0.5641 \\
\hline$\gamma$ & $\mathbf{0 . 9 6 9 3}$ & 0.5039 & 1.4347 \\
\hline$\delta$ & $\mathbf{1 . 4 1 7 7}$ & 1.0082 & 1.8273 \\
\hline
\end{tabular}

$$
h_{c w-c b}=K \frac{k_{b}}{l_{\psi}}\left(K_{\alpha} \frac{\omega D^{2}}{a_{b}}\right)^{\alpha}\left(K_{\beta} \frac{l_{\psi}}{D}\right)^{\beta}\left(K_{\gamma}[H U] \%\right)^{\gamma}\left(K_{\delta} \frac{T_{w} k_{b}^{0.4} c_{p b}^{0.6}}{\rho_{b}^{0.4} D^{2.8}}\right)^{\delta}
$$

In Eq. $16, K, K_{\alpha}, \ldots, K_{\delta}, \alpha, \ldots, \delta$ are the model parameters, $\omega=\frac{2 \pi}{60} N$ is the kiln angular speed, $a_{b}=\frac{k_{b}}{\rho_{b} c_{p b}}$ is the bulk diffusivity, $[H U] \%$ is the kiln filling degree in percent. Note that: (1) the constants $K_{\alpha}, K_{\beta}, K_{\gamma}$, and $K_{\delta}$, used to facilitate the determination of the model parameters, were respectively set at $10^{-3}, 10,10^{-2}$, and $10^{-4},(2)$ the effective bed conductivity, $k_{b}$, can be determined at the heating temperature at the wall, $T_{w}$, if the solids temperature is unknown. The model parameters given in Table 4 were determined with a Matlab using a nonlinear method based on iterative least squares estimation to minimize the discrepancy between the experimental results and the model calculations. These parameters are given with a confidence level of $95 \%$. Figure 12 shows a comparison of the experimental results with the model calculations. Even though there are a few discrepancies, in general there is a good agreement between model calculations and experimental results within the $20 \%$ margins. If the model aims to be applied beyond its limits of validity, this must be done with a great deal of caution. It should be mentioned, however, that this model is only valid outside the field of radiation-dominated heat transfer, which is usually the case at low to medium heating temperatures. However, in the future the correlation presented here can be suitably modified to better take into account the effect of radiation at very high temperature. This will require extending the experimental matrix to higher heating temperatures at the wall, while at the same time varying the other parameters studied.

The set of parameters determined for Eq. 16 from the experimental results implies that the wall-to-solid heat transfer increases with the kiln rotational speed, the filling degree, and the heating temperature at the wall. Eventually, the coefficient also increases following an increase in the wall-to-solid contact area, possibly due to the presence of lifters. The latter trends, even if not strictly established while analyzing the actual results, were clearly established in a preliminary analysis ([39] chap. 6). 


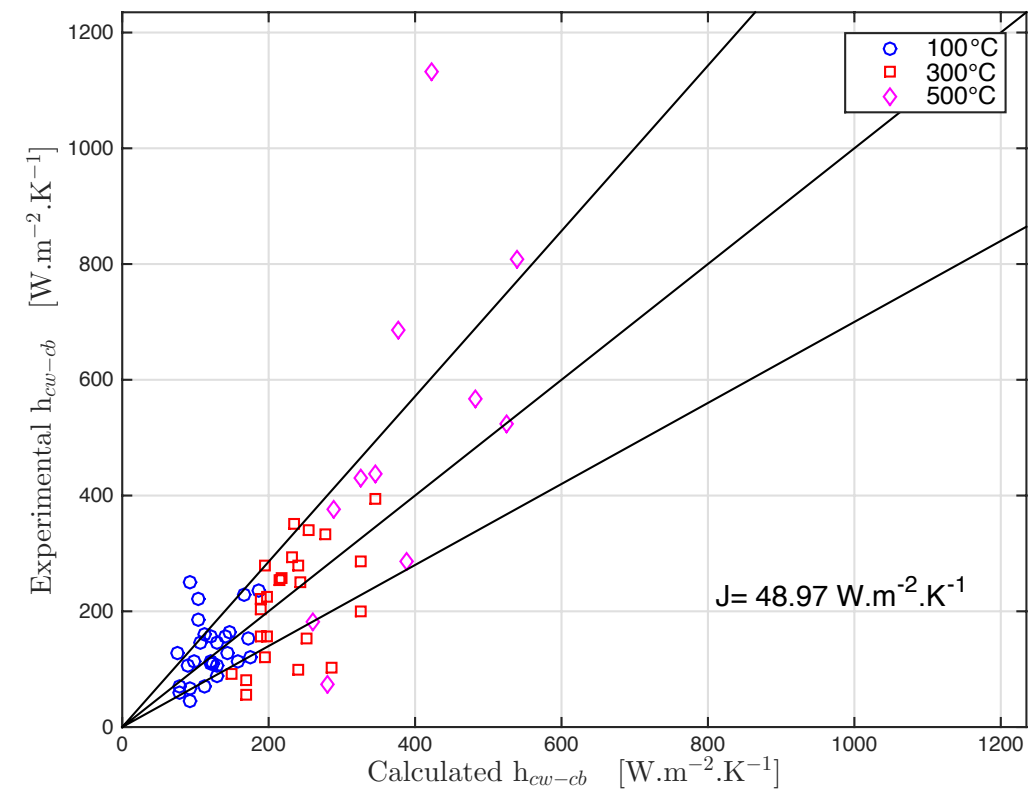

Figure 12: Comparison of experimental wall-to-solid heat transfer coefficients with predictions from Eq.16 using the set of parameters given in Table 4 . Solid lines are $\pm 20 \%$ margins. See next section for the definition of the performance criterion $\mathrm{J}$.

\subsubsection{Predictive performance of selected models from the literature}

In this section, the experimental results are compared to the predictions of the models defined by $[25,30,34]$ as given respectively in Eqs. 1, 2 and 3. Figure 13 shows the comparison between experimental results and model predictions.

a) Wes [25]

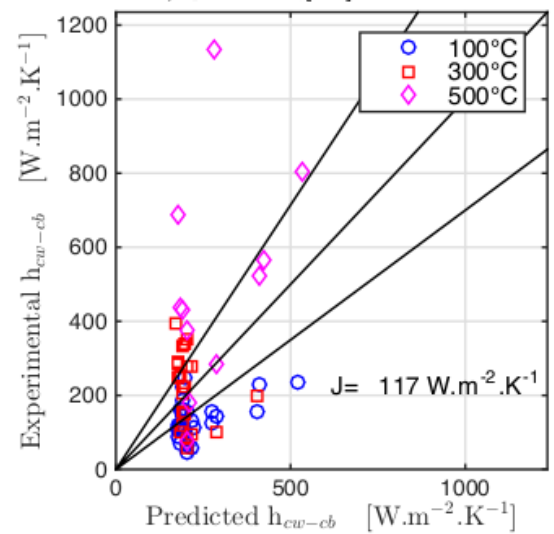

b) Tscheng [30]

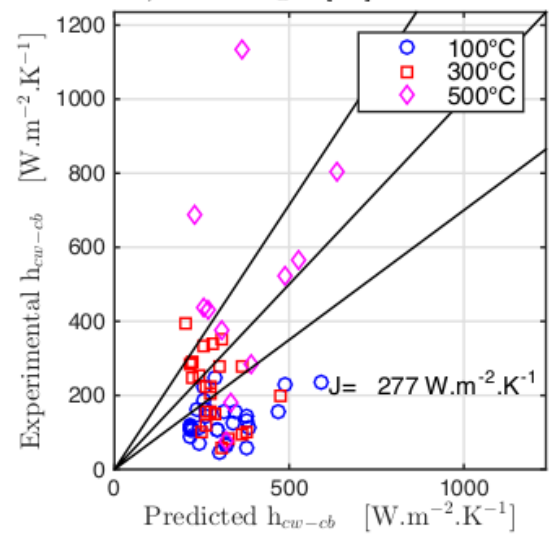

c) $\mathrm{Li}[34]$

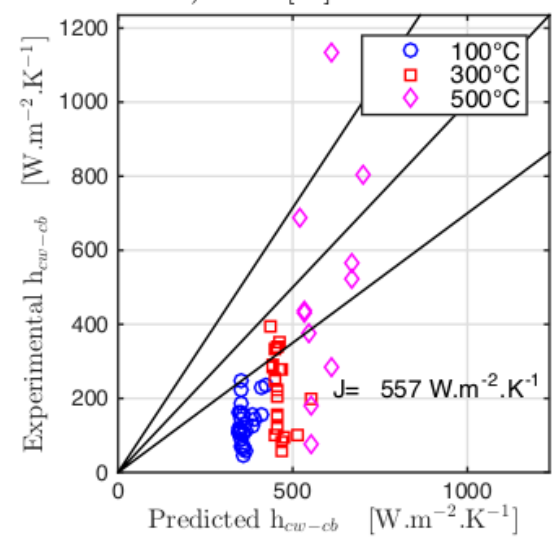

Figure 13: Comparison of the experimental wall-to-solid heat transfer coefficients with the predicted values from the correlations of: a) [25], b) [30], c) [34]. Solid lines are $\pm 20 \%$ margins.

In order to better assess the predictive performance of the different models, a criterion in performance assessments, J, is defined as follows:

$$
J=\frac{1}{N_{T}} \sum_{i=1}^{i=N_{T}} \frac{\left(h_{c w-c b}^{i_{e x p}}-h_{c w-c b}^{i_{c a l c}}\right)^{2}}{h_{c w-c b}^{i_{e x p}}}
$$

This criterion can be defined as the sum of the relative square errors between predictions and experimental results, relative to the number of experiments, $N_{T}$. The lower the value of this criterion, the better the predictive performance of the model. Although it must be admitted that the 3 selected models give results in about the same order of magnitude as the experimental results, these results are significantly scattered 
across the $20 \%$ margins. In general these models fail to represent the variation of the coefficient with the operating parameters. None of these correlations explicitly account for the operating temperature; indeed the bed thermal conductivity varies very little as the temperatures is increased to $500^{\circ} \mathrm{C}$. As a result, the predictions are virtually constant; this is notably the case for the predictions calculated from [25] correlation, which mostly vary with the rotational speed and nothing else. It must be noted, however, that at $100^{\circ} \mathrm{C}$ there is quite good agreement between the predicted and experimental results. In the case of the predictions obtained from [30] correlation, the dispersal around the parity line appears greater than that previously observed; indeed Eq.2 takes into account the filling degree, rotational speed and temperature through the thermal diffusivity. The predictions calculated from [34] correlation display 3 patterns that are associated with the 3 heating temperatures set at the wall in this study, very similar to the results from the correlation proposed by [25]; no other variation is observed. Among the 3 selected models, as shown in Figure 13, the lowest value of the criterion $\mathrm{J}$ is obtained from Eq.1 by [25]. Nonetheless, as given in Figure 12, it should be pointed out that these criteria are 2 to 10 times higher than that obtained from Eq.16 while using the set of parameters given in Table 4 .

\section{Conclusions}

In this study, the heat transfer coefficient between the wall and solids was investigated. The coefficient was determined from a heat balance with the use of experimental data comprising power supplied for the heating and temperature profiles measured within a continuously fed rotary kiln. The contact areas, through which heat transmission occurs, were defined so that the presence of lifters, as well as surface roughness are taken into account. The main results of the above study can be summarized as follows:

- The wall-to-solid heat transfer coefficient was found to be of the order of magnitude about $10^{2} \mathrm{~W} \cdot \mathrm{m}^{-2} \cdot \mathrm{K}^{-1}$. It may vary by up to $24 \%$, over the temperature range set at the wall examined in this study, if the radiative heat transfer is neglected. Convection has little or no effect on this coefficient, in this case where there is no axial forced flow of gas.

- The effect of the operating parameters on the coefficient are not always obvious. However, in this study as also shown in the preliminary analysis ([39] chap. 6), and as expected intuitively, the effect of the lifter design on the coefficient suggests a critical lifter design that may be optimized in order to enhance heat transfer. The coefficient is also found to increase with the rotational speed, especially at a constant filling degree.

- From the experimental results, a model based on dimensional analysis is proposed for the prediction of the wall-to-solid heat transfer coefficient within rotary kilns. The correlation is valid for a wide range of operating conditions. However, it should be applied to kilns operated at low to medium temperatures to have full confidence in the results. The proposed correlation successfully represents the majority of experimental results, at least better than the set of correlations selected from the literature.

\section{Acknowledgements}

We gratefully acknowledge Clément HAUSTANT for his kind help in this experimental work. 


\section{List of symbols}

\begin{tabular}{|c|c|c|}
\hline $\mathrm{A}$ & Heat transfer area & $\mathrm{m}^{2}$ \\
\hline $\mathrm{a}$ & Thermal diffusivity & $\mathrm{m}^{2} \cdot \mathrm{s}^{-1}$ \\
\hline$c_{p}$ & Specific heat capacity & $\mathrm{J} \cdot \mathrm{kg}^{-1} \cdot \mathrm{K}^{-1}$ \\
\hline$d_{\text {eff }}$ & Length of lifter transferring heat & $\mathrm{m}$ \\
\hline $\mathrm{D}$ & Kiln internal diameter & $\mathrm{m}$ \\
\hline $\mathrm{D}_{e}$ & Equivalent diameter & $\mathrm{m}$ \\
\hline$d_{p}$ & Particle diameter & $\mathrm{m}$ \\
\hline $\mathrm{E}$ & Irradiance & $\mathrm{W} \cdot \mathrm{m}^{-2}$ \\
\hline $\mathrm{F}$ & View factor & - \\
\hline $\mathrm{h}$ & Heat transfer coefficient & $\mathrm{W} \cdot \mathrm{m}^{-2} \cdot \mathrm{K}^{-1}$ \\
\hline$h_{\text {exit }}$ & Exit dam height & $\mathrm{m}$ \\
\hline$h_{\text {bed }}$ & Bed depth & $\mathrm{m}$ \\
\hline HTC & Heat transfer coefficient & $\mathrm{W} \cdot \mathrm{m}^{-2} \cdot \mathrm{K}^{-1}$ \\
\hline $\mathrm{HU}[\%]$ & Hold-up volume fraction or filling degree & - \\
\hline $\mathrm{J}$ & Performance criterion & $\mathrm{K}$ \\
\hline $\mathrm{J}$ & Radiosity & $\mathrm{W} \cdot \mathrm{m}^{-2}$ \\
\hline $\mathrm{k}$ & Thermal conductivity & $\mathrm{W} \cdot \mathrm{m}^{-1} \cdot \mathrm{K}^{-1}$ \\
\hline$K, K_{\alpha}, K_{\beta}, K_{\gamma}, K_{\delta}$ & Model parameter & - \\
\hline $\mathrm{L}$ & Kiln length & $\mathrm{m}$ \\
\hline$l_{\psi}$ & Circumference of the covered wall & $\mathrm{m}$ \\
\hline$l_{c t r l}$ & Length between two sections within the kiln & $\mathrm{m}$ \\
\hline$l_{g}$ & Effective wall-to-gas contact length along the cross section between & $\mathrm{m}$ \\
\hline$l_{\text {lift }}$ & Circumference between 2 consecutive lifters & $\mathrm{m}$ \\
\hline LMTD & Logarithmic mean temperature difference & K \\
\hline$\dot{\mathrm{M}}$ & Mass flow rate & $\mathrm{kg} \cdot \mathrm{h}^{-1}$ \\
\hline $\mathrm{N}$ & Kiln rotational speed & $\mathrm{rpm}$ \\
\hline NA & Not available & - \\
\hline NL & No lifters & - \\
\hline $\mathrm{N}_{T}$ & Total number of experiments & - \\
\hline $\operatorname{Pr}$ & Prandtl number & - \\
\hline $\mathrm{R}$ & Kiln radius & $\mathrm{m}$ \\
\hline$R e_{w}$ & Rotational Reynolds number & - \\
\hline $\mathrm{rpm}$ & Rotation per minute & - \\
\hline RL & Rectangular lifters & - \\
\hline $\mathrm{S}$ & Kiln slope & degree \\
\hline$S_{0}$ & Power supplied & $\mathrm{W}$ \\
\hline SL & Straight lifters & - \\
\hline $\mathrm{t}$ & Time & $\mathrm{h}$ \\
\hline $\mathrm{T}$ & Temperature & $\mathrm{K}$ \\
\hline $\mathrm{TC}$ & Thermocouple & - \\
\hline$t_{c}$ & Wall-to-solid contact time & $\mathrm{s}$ \\
\hline w-t-g & Wall-to-gas & - \\
\hline$w-t-s$ & Wall-to-solid & - \\
\hline $\mathrm{z}$ & Axial position & $\mathrm{m}$ \\
\hline
\end{tabular}




\section{Greek letters}

$\begin{array}{ccc}\alpha, \beta, \gamma, \delta & \text { Fitting parameters } & - \\ \alpha, \beta, \gamma & \text { Coefficients relative to the smoothness of surface } & - \\ \Delta t & t_{f}-t_{i} & \mathrm{~s} \\ \epsilon_{0} & \text { Solid bulk porosity } & - \\ \varepsilon & \text { Emissivity } & \mathrm{kg} \cdot \mathrm{m}^{-1} \cdot \mathrm{s}^{-1} \\ \mu & \text { Dynamic viscosity } & \mathrm{kg} \cdot \mathrm{m}^{-3} \\ \rho & \text { Density } & - \\ \tau_{g} & \text { Fraction of irradiation transmitted through the gas } & \mathrm{W} \\ \Phi & \text { Heat transfer flux } & \mathrm{W} \cdot \mathrm{m}^{-1} \\ \phi & \text { Heat transfer flux per unit length } & \mathrm{kg} \cdot \mathrm{m}^{-3} \\ \rho_{t r u e} & \text { Particle density } & \mathrm{mm} \\ \chi & \text { Gas film thickness } & \mathrm{rad} \\ \psi & \text { Filling angle } & \mathrm{m}{ }^{3} \\ \Omega & \text { Volume } & \mathrm{rad} / \mathrm{s}\end{array}$

\section{Subscripts}

b

calc

$\mathrm{cb}$

ctrl

cV

$\mathrm{cw}$

eff

ew

$\exp$

ext

f

fs

$\mathrm{G}, \mathrm{g}$

i

ins

int

gbd

gbu

gu

lift

loss

$\mathrm{r}$

$\mathrm{S}$

$\mathrm{W}, \mathrm{w}$

\section{Ambiant}

Bulk bed of solids

Calculated

Covered bed

Control (volume)

Convection

Covered wall

Effective

Exposed wall

Experimental

External wall (insulation)

Final

Falling solids particle

Gas

Initial

Insulation

Internal wall (insulation)

Gas at the bottom in the left side of the kiln cross section

Gas at the top in the right side of the kiln cross section

Gas at the top in the left side of the kiln cross section

Lifters

Losses

Radiation

Bulk bed of solids

Wall 


\section{Appendices}

\section{A Calculation of the heat losses through the insulation}

The heating zones are thermally insulated from the surroundings using a $110 \mathrm{~mm}$ multilayer insulation composed of alumina-based fiber. The heat loss per unit length of an insulated kiln tube within the heated zone(s) is estimated as follows:

$$
\phi_{\text {ins }}=\pi D_{\text {ins }}^{\text {ext }} \frac{\left(T_{w}-T_{a}\right)}{R_{\text {total }}}
$$

with the heat transfer resistance defined as follows:

$$
R_{\text {total }}=R_{\text {ins }}+\frac{1}{h_{\text {air }}}
$$

The thermal conductivity for insulation material was found in the literature [53]; a value of $k_{\text {ins }}=0.125 \mathrm{~W} \cdot \mathrm{m}^{-1} \cdot \mathrm{K}^{-1}$ was used for the calculations. The heat transfer resistance due to insulation is determined as follows:

$$
R_{i n s}=\frac{D_{i n s}^{e x t}}{2 k_{i n s}} \ln \left(\frac{D_{i n s}^{e x t}}{D_{i n s}^{\text {int }}}\right)
$$

The air side heat transfer coefficient is determined as follows:

$$
h_{\text {air }}=h^{r}+h^{c v}
$$

The heat transfer coefficient due to radiation at the insulation external wall is determined as follows:

$$
h^{r}=\sigma \varepsilon_{i n s}^{e x t} \frac{\left(\bar{T}^{4}-T_{a}^{4}\right)}{\left(\bar{T}-T_{a}\right)}
$$

where the average temperature is $\bar{T}=\frac{T_{a}+T_{i n s}^{e x t}}{2}$, with $T_{i n s}^{e x t}$ the temperature at the insulation cladding surface, and the value used in the calculation for the emissivity of the latter surface is $\varepsilon_{i n s}^{e x t}=0.05$. The convective heat transfer coefficient is calculated based on a correlation by Churchill and Chu for the free convection from horizontal cylinders, but restricted to the laminar range of $10^{-6}<\operatorname{Gr} \operatorname{Pr}<10^{9}$ :

$$
N u_{d}=0.36+\frac{0.518\left(\mathrm{Gr}_{\mathrm{d}} \mathrm{Pr}\right)^{1 / 4}}{\left[1+(0.0559 / \mathrm{Pr})^{9 / 16}\right]^{4 / 9}}, h^{c v}=\frac{N u_{d} k_{a i r}}{D_{\text {ins }}^{\text {ext }}}
$$

\section{B Bed depth profile measurements}

The aim of the bed depth profile measurements was to measure precisely the bed depth in particular within the heating zone 2 of the kiln. For that purpose a measuring rod was designed. The rod is equipped with ten stems measuring $50 \mathrm{~mm}$ in length and $5 \mathrm{~mm}$ in diameter, and it can be easily fitted inside the kiln using the existing system used to hold the TC measuring rod. The stems are attached to the rod using boss-heads. The measuring rod and the stems' positions (numbered from 1 to 10) are shown in Figure 14. Note that positions 1, 3, 5, 7 and 9 highlighted in gray correspond respectively to sections S1 to S5 identified in Figure 3.

Figure 15 sums up the main steps of the procedure. Each run was repeated 2 or 3 times. The following experimental procedure was used to measure the bed depth:

1. The stems are cleaned and coated with glue over the whole length.

2. The measuring rod is then installed inside the kiln and its support fixed to the kiln frame.

3. Steady flow conditions are achieved:

(a) Before starting the run, the following operating parameters must be set: a) the suitable lifter structure, either straight (SL) or rectangular (RL) lifters, or none (NL); b) the exit dam of either $13.5,23.5$ or $33.5 \mathrm{~mm}$, or none; c) the kiln must be tilted to the desired slope; d) the kiln rotational speed $\mathrm{N}$ and desired solids mass flow rate are set to the desired value by adjusting the corresponding motor rotational frequency. The rotary kiln is then started and the feed hopper regularly filled with the operating solids to keep it topped up till the end of the run. 


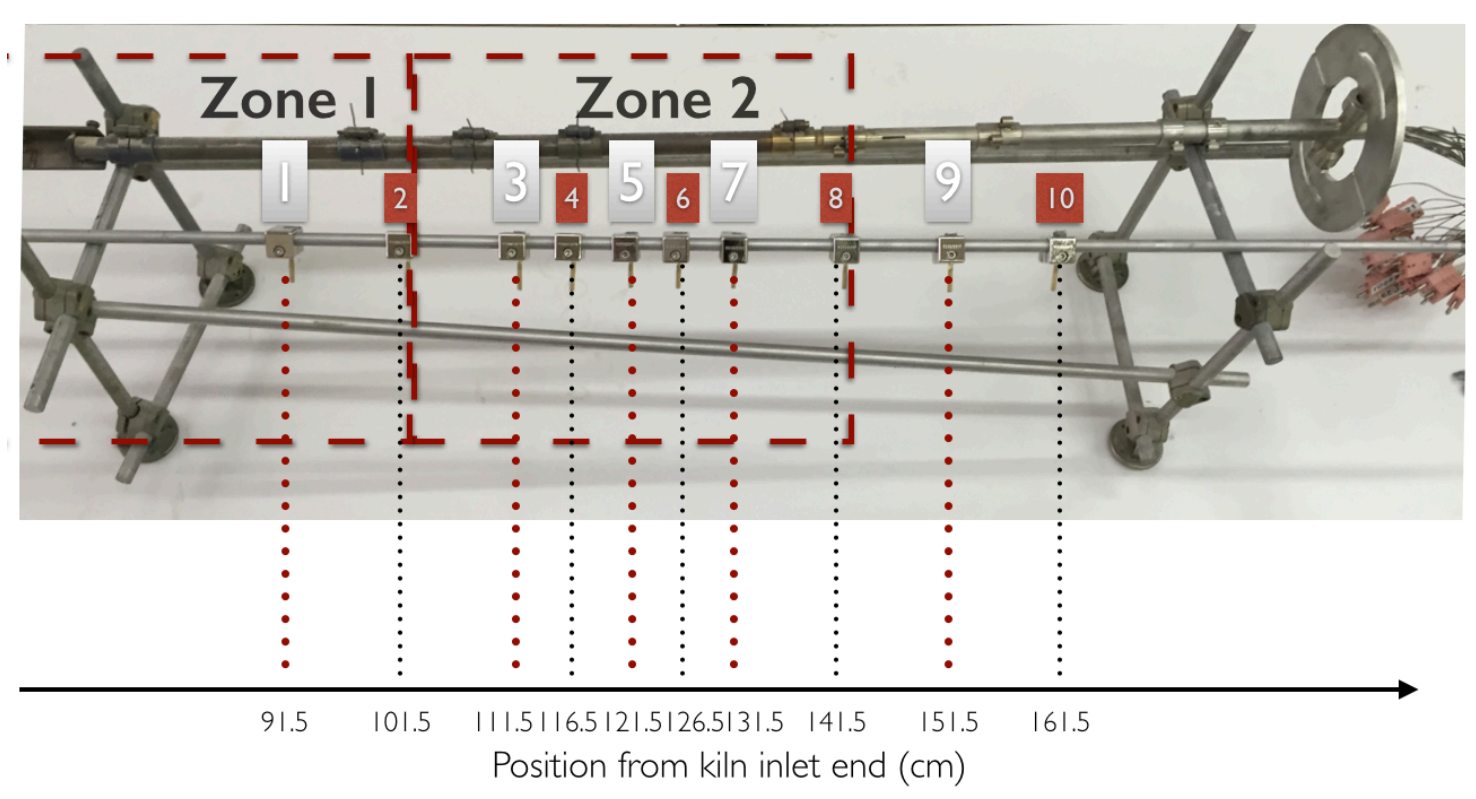

Figure 14: Bed depth measuring rod and position of the stems.

(b) The system is run until it reaches steady-state conditions, usually after 2 to 4 hours. The steady state is assumed to be reached when at least three consecutive measurements of the flow rate at the kiln outlet are equal within a margin of $\pm 0.05 \mathrm{~kg} \cdot \mathrm{h}^{-1}$.

4. The bed burden is discharged and weighed: The rotary kiln rotation is stopped and the screw feeder disabled at the same time. If present, the exit dam is removed. Then only the kiln rotation is started again and the solids are discharged. The collected solids which constitute the kiln hold-up are weighed.

5. The measuring rod is removed from the kiln and the height of particles clinging to the stems are measured using a slipping caliper.

Figure 16 displays the resulting bed depth profiles in zone 2 determined either by experimental measurements or with the use of Eqs. 11 and 12.

\section{Uncertainty calculations}

Let $f$ be a function dependent on $p$ independent variables: $f\left(x_{1}, x_{2}, \ldots, x_{j}, \ldots, x_{p}\right)$. The uncertainty of the function $f$ can be determined as follows [54]:

$$
\left.(\Delta f)^{2}=j=1\right] p \sum\left[\left(\frac{\partial f}{\partial x_{j}}\right)^{2}\left(\Delta x_{j}\right)^{2}\right]
$$

where $\Delta x_{j}$ is the uncertainty of the independent variable.

In our case the independent variables were measured, and the value of their uncertainties were determined from the two existing approaches [54]: Type A and Type B evaluations. Type A estimates the uncertainty using statistics; this was used when repeated readings were available. Type B estimates the uncertainty from calibration certificates, manufacturer's specifications, or calculations.

The uncertainties of the variables used were determined to calculate the uncertainty of the heat transfer coefficient in this study. The uncertainty of variables are given in Table 5.

Table 5: Calculated uncertainties.

\begin{tabular}{ccccc}
\hline Temperature & Power & Angular & \multicolumn{2}{c}{ Length } \\
\hline$\Delta T_{g, b, w}\left[{ }^{\circ} \mathrm{C}\right]$ & $\Delta S_{o}[\mathrm{~kW}]$ & $\Delta \psi[\mathrm{rad}]$ & $\Delta h_{\text {bed }}[\mathrm{mm}]$ & $\Delta$ Length, $\Delta D, \Delta R, \Delta l_{\text {ctrl }}, \ldots[\mathrm{mm}]$ \\
\hline 0.1325 & 0.0058 & 0.0876 & 0.0011 & $5.7710^{-5}$ \\
\hline
\end{tabular}


I. Coat each stem with glue
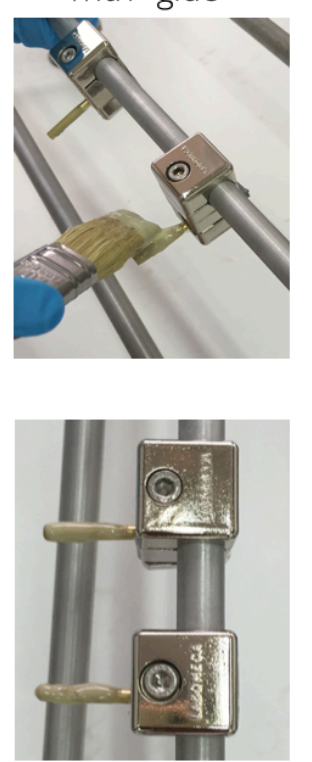

2. Insert the measuring rod inside the kiln tube

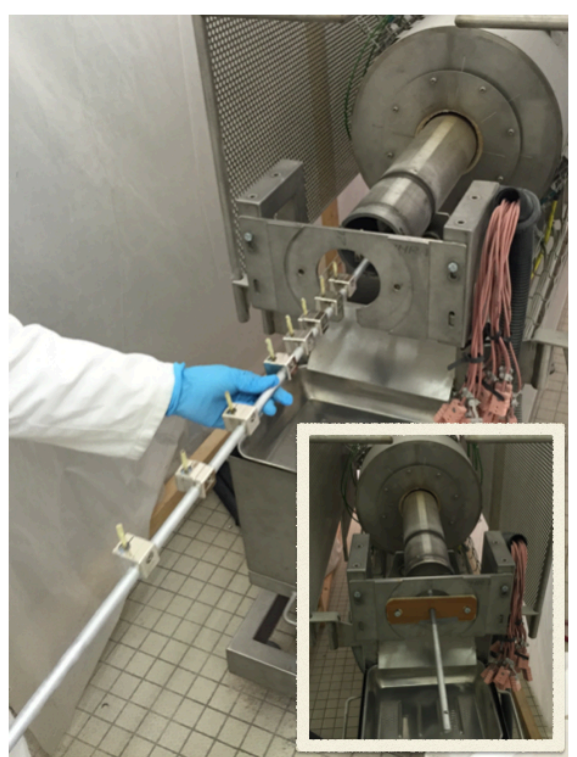

3. Measurement of the bed depth
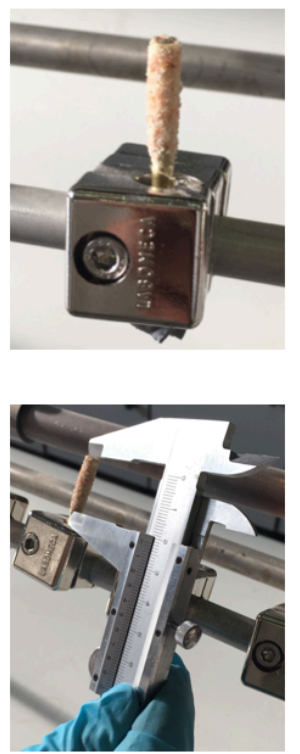

Figure 15: Experimental procedure for the bed depth measurement.

\section{References}

[1] A. A. Boateng, Rotary kilns transport phenomena and transport processes, Elsevier/ButterworthHeinemann, Amsterdam; Boston, 2008.

[2] R. T. Bui, J. Perron, M. Read, Model-based optimization of the operation of the coke calcining kiln, Carbon 31 (7) (1993) 1139-1147. doi:10.1016/0008-6223(93)90067-K.

URL http://www.sciencedirect.com/science/article/pii/000862239390067K

[3] R. T. Bui, G. Simard, A. Charette, Y. Kocaefe, J. Perron, Mathematical modeling of the rotary coke calcining kiln, The Canadian Journal of Chemical Engineering 73 (4) (1995) 534-545. doi:10.1002/cjce.5450730414.

URL http://onlinelibrary.wiley.com/doi/10.1002/cjce.5450730414/abstract

[4] M. A. Martins, L. S. Oliveira, A. S. Franca, Modeling and simulation of petroleum coke calcination in rotary kilns, Fuel 80 (11) (2001) 1611-1622. doi:10.1016/S0016-2361(01)00032-1.

URL http://www.sciencedirect.com/science/article/pii/S0016236101000321

[5] A. Chatterjee, A. V. Sathe, P. K. Mukhopadhyay, Flow of materials in rotary kilns used for sponge iron manufacture: Part II. Effect of kiln geometry, Metallurgical Transactions B 14 (3) (1983) 383-392. doi:10.1007/BF02654357.

URL http://link.springer.com/article/10.1007/BF02654357

[6] A. Atmaca, R. Yumrutas, Analysis of the parameters affecting energy consumption of a rotary kiln in cement industry, Applied Thermal Engineering 66 (1-2) (2014) 435-444. doi:10.1016/j.applthermaleng.2014.02.038.

URL http://www.sciencedirect.com/science/article/pii/S1359431114001306

[7] M. Debacq, P. Thammavong, S. Vitu, D. Ablitzer, J.-L. Houzelot, F. Patisson, A hydrodynamic model for flighted rotary kilns used for the conversion of cohesive uranium powders, Chemical Engineering Science 104 (2013) 586-595. doi:10.1016/j.ces.2013.09.037.

URL http://linkinghub.elsevier.com/retrieve/pii/S0009250913006568

[8] M. Debacq, S. Vitu, D. Ablitzer, J.-L. Houzelot, F. Patisson, Transverse motion of cohesive powders in flighted rotary kilns: Experimental study of unloading at ambient and high temperatures, Powder Technology 245 (2013) 56-63. doi:10.1016/j.powtec.2013.04.007.

URL http://linkinghub.elsevier.com/retrieve/pii/S0032591013002647 
$3^{\circ}, 2 \mathrm{rpm}, 0.9 \mathrm{~kg} / \mathrm{h}, 23.5 \mathrm{~mm}, \mathrm{NL}$

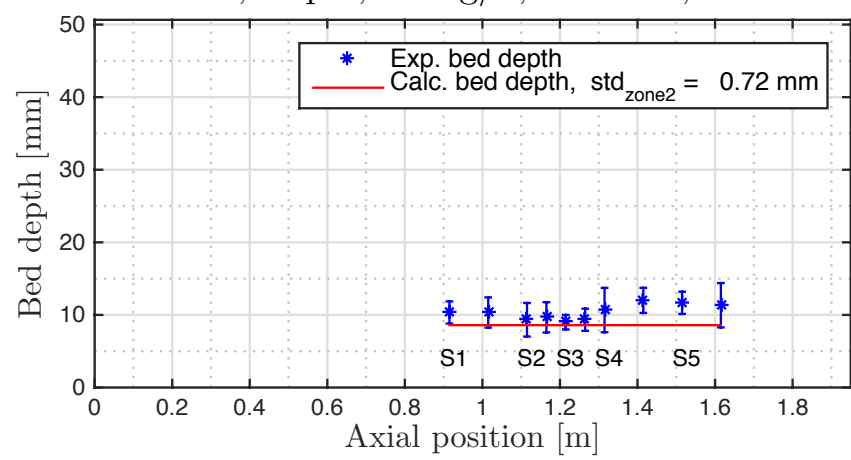

$3^{\circ}, 2 \mathrm{rpm}, 1.9 \mathrm{~kg} / \mathrm{h}, 23.5 \mathrm{~mm}, \mathrm{NL}$

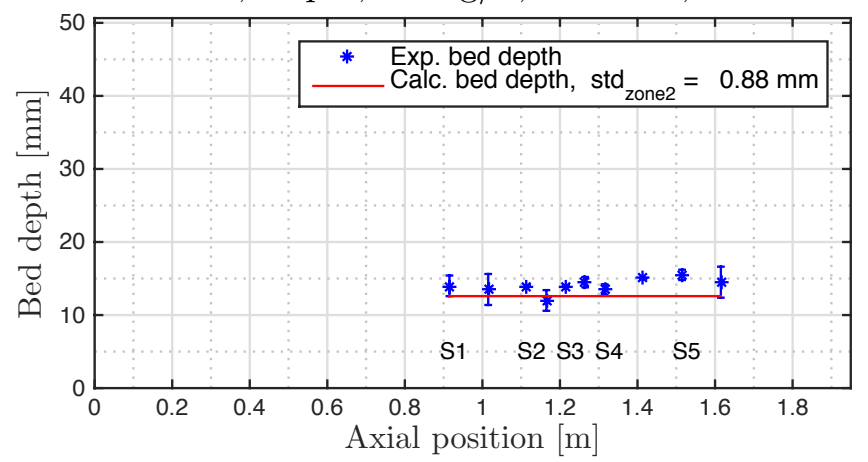

$3^{\circ}, 2 \mathrm{rpm}, 2.5 \mathrm{~kg} / \mathrm{h}, 23.5 \mathrm{~mm}, \mathrm{NL}$

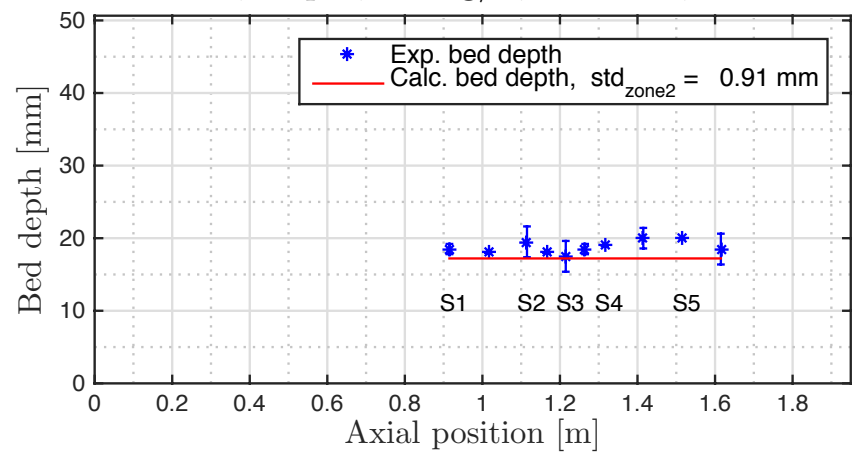

$3^{\circ}, 2 \mathrm{rpm}, 0.9 \mathrm{~kg} / \mathrm{h}, 33.5 \mathrm{~mm}, \mathrm{NL}$

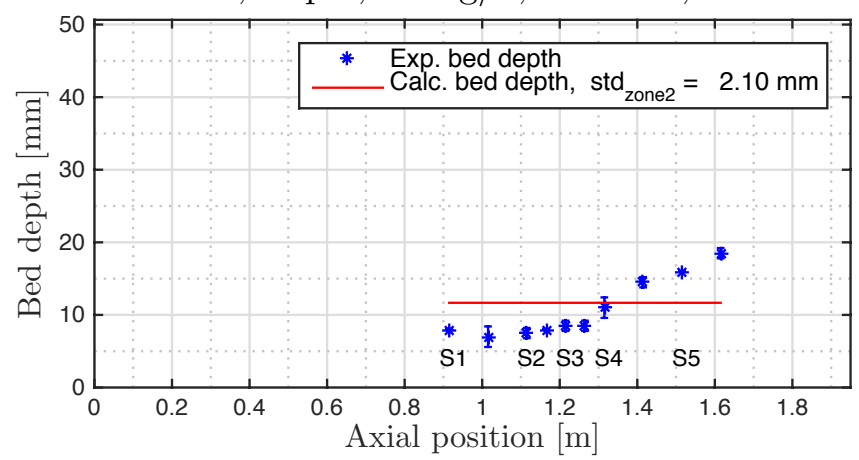

$3^{\circ}, 2 \mathrm{rpm}, 1.9 \mathrm{~kg} / \mathrm{h}, 33.5 \mathrm{~mm}, \mathrm{NL}$

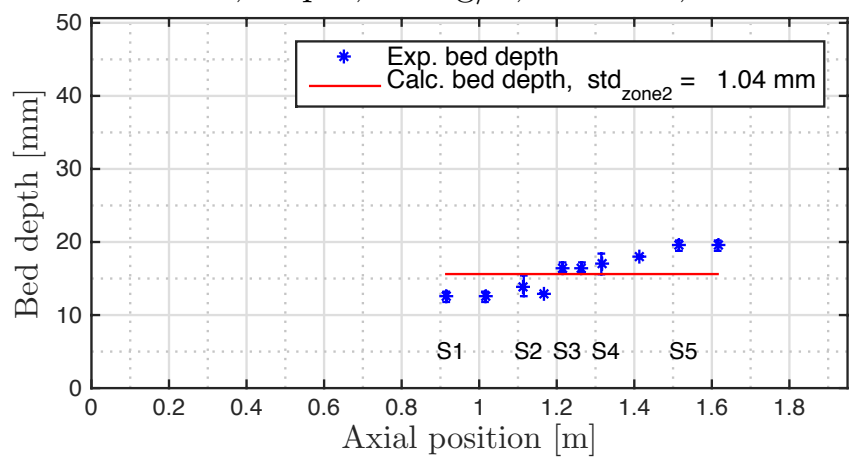

$3^{\circ}, 2 \mathrm{rpm}, 2.5 \mathrm{~kg} / \mathrm{h}, 33.5 \mathrm{~mm}, \mathrm{NL}$

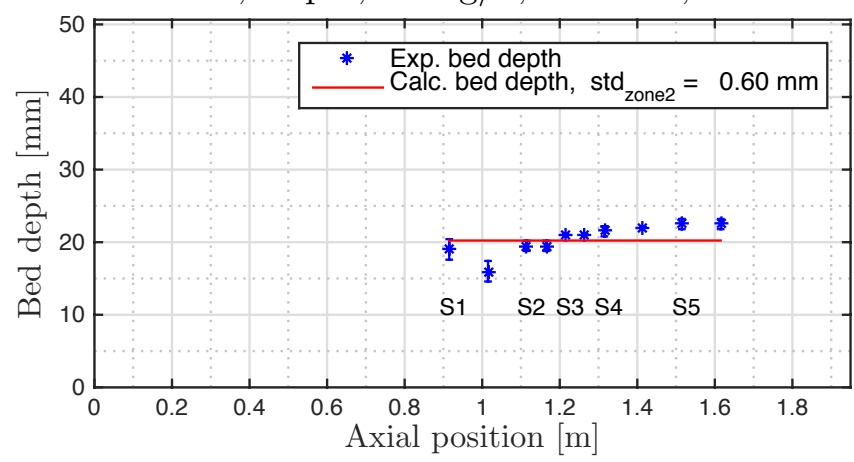

Figure 16: Experimental and calculated bed depth profiles in zone 2 for varying operating conditions without lifters. Eq.12 is used to determine of the kiln bed depth. The standard deviation of the calculated bed depth with respect to the experimental measurements is also given. 
[9] F. Geng, Y. Li, X. Wang, Z. Yuan, Y. Yan, D. Luo, Simulation of dynamic processes on flexible filamentous particles in the transverse section of a rotary dryer and its comparison with ideo-imaging experiments, Powder Technology 207 (1-3) (2011) 175-182. doi:10.1016/j.powtec.2010.10.027.

URL http://linkinghub.elsevier.com/retrieve/pii/S0032591010005772

[10] F. Geng, Y. Li, L. Yuan, M. Liu, X. Wang, Z. Yuan, Y. Yan, D. Luo, Experimental study on the space time of flexible filamentous particles in a rotary dryer, Experimental Thermal and Fluid Science 44 (2013) 708-715. doi:10.1016/j.expthermflusci.2012.09.011.

URL http://www.sciencedirect.com/science/article/pii/S0894177712002518

[11] T. Suzuki, T. Okazaki, K. Yamamoto, H. Nakata, O. Fujita, Improvements in Pyrolysis of Wastes in an Externally Heated Rotary Kiln (Measurement of the Overall Heat Transfer Coefficient form the Wall to the Wastes), Transactions of the Japan Society of Mechanical Engineers Series B 74 (743) (2008) 1586-1592, 1st Report, Measurement of the Overall Heat Transfer Coefficient form the Wall to the Wastes.

[12] B. Colin, J. L. Dirion, P. Arlabosse, S. Salvador, Wood chips flow in a rotary kiln: experiments and modeling, Chemical Engineering Research and Designdoi:10.1016/j.cherd.2015.04.017.

URL http://www.sciencedirect.com/science/article/pii/S0263876215001215

[13] J. Matthes, J. Hock, P. Waibel, A. Scherrmann, H.-J. Gehrmann, H. Keller, A high-speed camera based approach for the on-line analysis of particles in multi-fuel burner flames, Experimental Thermal and Fluid Science 73 (2016) 10-17. doi:10.1016/j.expthermflusci.2015.08.017.

URL http://linkinghub.elsevier.com/retrieve/pii/S0894177715002289

[14] P. Thammavong, M. Debacq, S. Vitu, M. Dupoizat, Experimental Apparatus for Studying Heat Transfer in Externally Heated Rotary Kilns, Chemical Engineering \& Technology 34 (5) (2011) 707-717. doi:10.1002/ceat.201000391.

URL http://onlinelibrary.wiley.com/doi/10.1002/ceat.201000391/abstract

[15] A. Boateng, P. Barr, A thermal model for the rotary kiln including heat transfer within the bed, International Journal of Heat and Mass Transfer 39 (10) (1996) 2131 - 2147. doi:http://dx.doi.org/10.1016/0017-9310(95)00272-3.

URL http://www.sciencedirect.com/science/article/pii/0017931095002723

[16] L. Wachters, H. Kramers, The calcining of the sodium bicarbonate in a rotary kiln, Amsterdam, 1964, pp. $77-87$.

[17] J. Lehmberg, M. Hehl, K. Schügerl, Transverse mixing and heat transfer in horizontal rotary drum reactors, Powder Technology 18 (2) (1977) 149-163. doi:10.1016/0032-5910(77)80004-1.

URL http://www.sciencedirect.com/science/article/pii/0032591077800041

[18] P. Lybaert, Wall-particles heat transfer in rotating heat exchangers, International Journal of Heat and Mass Transfer 30 (8) (1987) 1663-1672. doi:10.1016/0017-9310(87)90312-7.

URL http://www.sciencedirect.com/science/article/pii/0017931087903127

[19] T. Suzuki, T. Okazaki, K. Yamamoto, H. Nakata, O. Fujita, Improvements in Pyrolysis of Wastes in an Externally Heated Rotary Kiln (Experimental Study on the Heat Transfer Enhancement), Transactions of the Japan Society of Mechanical Engineers Series B 74 (743) (2008) 1586-1592.

[20] F. Herz, I. Mitov, E. Specht, R. Stanev, Experimental study of the contact heat transfer coefficient between the covered wall and solid bed in rotary drums, Chemical Engineering Science 82 (2012) 312318. doi:10.1016/j.ces.2012.07.042.

URL http://linkinghub.elsevier.com/retrieve/pii/S0009250912004800

[21] H. N. Emady, K. V. Anderson, W. G. Borghard, F. J. Muzzio, B. J. Glasser, A. Cuitino, Hprediction of conductive heating time scales of particles in a rotary drum, Chemical Engineering Science 152 (2016) 45 - 54. doi:http://dx.doi.org/10.1016/j.ces.2016.05.022.

URL http://www.sciencedirect.com/science/article/pii/S0009250916302627 
[22] V. Scherer, M. Mönnigmann, M. O. Berner, F. Sudbrock, Coupled DEM-CFD simulation of drying wood chips in a rotary drum - Baffle design and model reduction, Fuel 184 (2016) 896-904. doi:10.1016/j.fuel.2016.05.054.

URL http://linkinghub.elsevier.com/retrieve/pii/S0016236116303696

[23] X. Liu, Z. Hu, W. Wu, J. Zhan, F. Herz, E. Specht, DEM study on the surface mixing and whole mixing of granular materials in rotary drums, Powder Technology 315 (2017) 438-444. doi:10.1016/j.powtec.2017.04.036.

URL http://linkinghub.elsevier.com/retrieve/pii/S0032591017303340

[24] A. Nafsun, F. Herz, E. Specht, H. Komossa, S. Wirtz, V. Scherer, X. Liu, Thermal bed mixing in rotary drums for different operational parameters, Chemical Engineering Science 160 (2017) 346-353. doi:10.1016/j.ces.2016.11.005.

URL http://linkinghub.elsevier.com/retrieve/pii/S0009250916305826

[25] G. W. J. Wes, A. A. H. Drinkenburg, S. Stemerding, Heat transfer in a horizontal rotary drum reactor, Powder Technology 13 (2) (1976) 185-192. doi:10.1016/0032-5910(76)85003-6.

URL http://www.sciencedirect.com/science/article/pii/0032591076850036

[26] F. Herz, I. Mitov, E. Specht, R. Stanev, Influence of operational parameters and material properties on the contact heat transfer in rotary kilns, International Journal of Heat and Mass Transfer 55 (25-26) (2012) 7941-7948. doi:10.1016/j.ijheatmasstransfer.2012.08.022.

URL http://www.sciencedirect.com/science/article/pii/S0017931012006436

[27] F. Herz, I. Mitov, E. Specht, R. Stanev, Influence of the Motion Behavior on the Contact Heat Transfer Between the Covered Wall and Solid Bed in Rotary Kilns, Experimental Heat Transfer 28 (2) (2015) 174-188. doi:10.1080/08916152.2013.854283.

URL http://dx.doi.org/10.1080/08916152.2013.854283

[28] D. R. Nhuchhen, P. Basu, B. Acharya, Investigation into overall heat transfer coefficient in indirectly heated rotary torrefier, International Journal of Heat and Mass Transfer 102 (2016) $64-76$. doi:http://dx.doi.org/10.1016/j.ijheatmasstransfer.2016.06.011.

URL http://www.sciencedirect.com/science/article/pii/S0017931016300357

[29] E.-U. Schlünder, Heat Transfer to Packed and Stirred Beds from the Surface of Immersed Bodies, Chemical Engineering and Processing 18 (1984) 31-53.

[30] S. H. Tscheng, A. P. Watkinson, Convective heat transfer in a rotary kiln, The Canadian Journal of Chemical Engineering 57 (4) (1979) 433-443. doi:10.1002/cjce.5450570405.

URL http://onlinelibrary.wiley.com/doi/10.1002/cjce.5450570405/abstract

[31] J. R. Ferron, D. K. Singh, Rotary kiln transport processes, AIChE Journal 37 (5) (1991) 747-758. doi:10.1002/aic.690370512.

URL http://onlinelibrary.wiley.com/doi/10.1002/aic.690370512/abstract

[32] Y. L. Ding, R. N. Forster, J. P. K. Seville, D. J. Parker, Some aspects of heat transfer in rolling mode rotating drums operated at low to medium temperatures, Powder Technology 121 (2-3) (2001) 168-181. doi:10.1016/S0032-5910(01)00343-6.

URL http://www.sciencedirect.com/science/article/pii/S0032591001003436

[33] L. Le Guen, F. Huchet, J. Dumoulin, A wall heat transfer correlation for the baffled-rotary kilns with secondary air flow and recycled materials inlet, Experimental Thermal and Fluid Sciencedoi:10.1016/j.expthermflusci.2014.01.020.

URL http://linkinghub.elsevier.com/retrieve/pii/S0894177714000296

[34] S.-Q. Li, L.-B. Ma, W. Wan, Q. Yao, A Mathematical Model of Heat Transfer in a Rotary Kiln ThermoReactor, Chemical Engineering \& Technology 28 (12) (2005) 1480-1489. doi:10.1002/ceat.200500241. URL http://onlinelibrary.wiley.com/doi/10.1002/ceat.200500241/abstract

[35] K. Malhotra, A. S. Mujumdar, Effect of Particle Shape on Particle-Surface Thermal Contact Resistance, Journal of Chemical Engineering of Japan 23 (4) (1990) 510-513. doi:10.1252/jcej.23.510. 
[36] J. P. Gorog, T. N. Adams, J. K. Brimacombe, Regenerative heat transfer in rotary kilns, Metallurgical Transactions B 13 (2) (1982) 153-163. doi:10.1007/BF02664572.

URL http://link.springer.com/article/10.1007/BF02664572

[37] W. D. Owens, G. D. Silcox, J. S. Lighty, X. X. Deng, D. W. Pershing, V. A. Cundy, C. B. Leger, A. L. Jakway, Thermal analysis of rotary kiln incineration: Comparison of theory and experiment, Combustion and Flame 86 (1-2) (1991) 101-114. doi:10.1016/0010-2180(91)90059-K.

URL http://www.sciencedirect.com/science/article/pii/001021809190059K

[38] M. Debacq, Étude et modélisation des fours tournants de défluoration et réduction du difluorure d'uranyle, Ph.D. thesis, Institut National Polytechnique de Lorraine, Nancy, France (2001).

URL https://tel.archives-ouvertes.fr/tel-00974273/document

[39] A. S. Bongo Njeng, Experimental study and modeling of hydrodynamic and heating characteristics of flighted rotary kilns, Ph.D. thesis, Ecole nationale des Mines d'Albi-Carmaux (Nov. 2015).

URL http://www. theses.fr/2015EMAC0009

[40] R. Bauer, E. U. Schluender, Effective radial thermal conductivity of packed beds with gas flow, Verfahrenstechnik (Mainz) 11 (10) (1977) 605-614.

URL https://scifinder.cas.org/scifinder/view/scifinder/scifinderExplore.jsf

[41] F. M. White, Heat and mass transfer, Addison-Wesley, Reading, Mass., 1988.

[42] S. M. Corporation, Incoloy alloy 800 (2014).

URL www.specialmetals.com

[43] S. M. Corporation, Inconel alloy 600 (2013).

URL www.specialmetals.com

[44] R. Siegel, J. R. Howell, Thermal Radiation Heat Transfer, 3rd Edition, McGraw-Hill Book Company, New-York, 1992.

[45] A. K. Oppenheim, Radiation analysis by the network method, Transactions of the ASME (78) (1956) $725-735$.

[46] T. L. Bergman, A. S. Lavine, F. P. Incropera, D. P. DeWitt, Fundamentals of Heat and Mass Transfer, 7th Edition, Wiley, 2011.

[47] J. P. Gorog, J. K. Brimacombe, T. N. Adams, Radiative heat transfer in rotary kilns, Metallurgical Transactions B 12 (1) (1981) 55-70. doi:10.1007/BF02674758.

URL http://link.springer.com/article/10.1007/BF02674758

[48] F. P. Incropera, D. P. DeWitt, T. L. Bergman, A. S. Lavine, Fundamentals of Heat and Mass Transfer, 2nd Edition, John Wiley \& Sons, Hoboken, NJ, 1985.

[49] A. S. Bongo Njeng, S. Vitu, M. Clausse, J. L. Dirion, M. Debacq, Effect of lifter shape and operating parameters on the flow of materials in a pilot rotary kiln: Part I. Experimental RTD and axial dispersion study, Powder Technology 269 (2015) 554-565. doi:10.1016/j.powtec.2014.03.066.

URL http://www.sciencedirect.com/science/article/pii/S0032591014002885

[50] A. S. Bongo Njeng, S. Vitu, M. Clausse, J. L. Dirion, M. Debacq, Effect of lifter shape and operating parameters on the flow of materials in a pilot rotary kiln: Part II. Experimental hold-up and mean residence time modeling, Powder Technology 269 (2015) 566-576. doi:10.1016/j.powtec.2014.05.070.

URL http://www.sciencedirect.com/science/article/pii/S0032591014005452

[51] A. S. Bongo Njeng, S. Vitu, M. Clausse, J. L. Dirion, M. Debacq, Effect of lifter shape and operating parameters on the flow of materials in a pilot rotary kiln: Part III. Up-scaling considerations and segregation analysis, Powder Technology 297 (2016) 415-428. doi:10.1016/j.powtec.2016.04.052.

URL http://www.sciencedirect.com/science/article/pii/S0032591016302200

[52] G. Delaplace, K. Loubière, F. Ducept, R. Jeantet, Dimensional Analysis of Food Processes, ISTE Press - Elsevier, 2015. 
[53] C. Langlais, S. Klarsfeld, Isolation thermique à température ambiante. Propriétés, Techniques de l'ingénieur. Matériaux fonctionnels 1 (BE9860).

[54] C. Croarkin, P. Tobias, NIST/SEMATECH e-Handbook of Statistical Methods, 2012. URL http://www.itl.nist.gov/div898/handbook/ 